Chapman University

Chapman University Digital Commons

Biology, Chemistry, and Environmental Sciences

Science and Technology Faculty Articles and

Faculty Articles and Research

Research

7-3-2017

Hydrogenation of Organic Matter as a Terminal Electron Sink Sustains High CO2:CH4 Production Ratios During Anaerobic Decomposition

Rachel M. Wilson

Malak M. Tfaily

Virginia I. Rich

Jason K. Keller

Scott D. Bridgham

See next page for additional authors

Follow this and additional works at: http://digitalcommons.chapman.edu/sees_articles

Part of the Biochemistry Commons, Botany Commons, Bryology Commons, Environmental Chemistry Commons, Organic Chemistry Commons, Other Biochemistry, Biophysics, and $\underline{\text { Structural Biology Commons, Other Plant Sciences Commons, and the Plant Biology Commons }}$ 


\section{Hydrogenation of Organic Matter as a Terminal Electron Sink Sustains High CO2:CH4 Production Ratios During Anaerobic Decomposition}

\section{Comments}

NOTICE: this is the author's version of a work that was accepted for publication in Organic Geochemistry. Changes resulting from the publishing process, such as peer review, editing, corrections, structural formatting, and other quality control mechanisms may not be reflected in this document. Changes may have been made to this work since it was submitted for publication. A definitive version will be subsequently published in Organic Geochemistry in 2017. DOI: 10.1016/j.orggeochem.2017.06.011

The Creative Commons license below applies only to this version of the article.

\section{Creative Commons License}

\section{(c) (1) $\Theta \Theta$}

This work is licensed under a Creative Commons Attribution-Noncommercial-No Derivative Works 4.0 License.

\section{Copyright}

Elsevier

\section{Authors}

Rachel M. Wilson, Malak M. Tfaily, Virginia I. Rich, Jason K. Keller, Scott D. Bridgham, Cassandra Medvedeff Zalman, Laura Meredith, Paul J. Hanson, Mark Hines, Laurel Pfeifer-Meister, Scott R. Saleska, Patrick Crill, William T. Cooper, Jeff P. Chanton, and Joel E. Kostka 


\section{Accepted Manuscript}

Hydrogenation of Organic Matter as a Terminal Electron Sink Sustains High $\mathrm{CO}_{2}: \mathrm{CH}_{4}$ Production Ratios During Anaerobic Decomposition

Rachel M. Wilson, Malak M. Tfaily, Virginia I. Rich, Jason K. Keller, Scott D. Bridgham, Cassandra Medvedeff Zalman, Laura Meredith, Paul J. Hanson, Mark Hines, Laurel Pfeifer-Meister, Scott R. Saleska, Patrick Crill, William T. Cooper, Jeff P. Chanton, Joel E. Kostka

PII: S0146-6380(16)30208-X

DOI: http://dx.doi.org/10.1016/j.orggeochem.2017.06.011

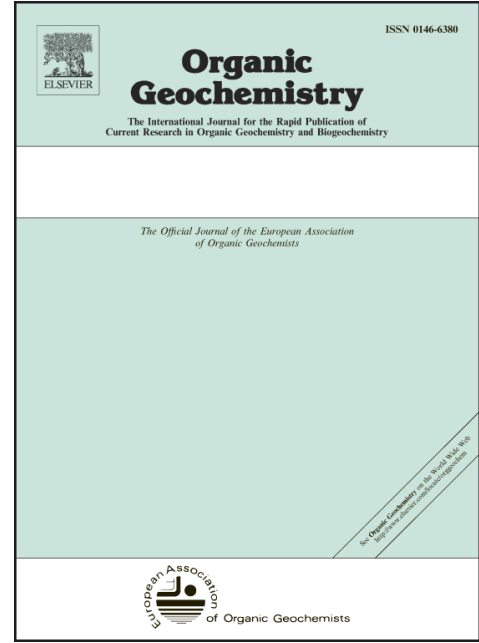

Reference: OG 3567

To appear in:

Organic Geochemistry

Received Date:

6 October 2016

Revised Date:

19 June 2017

Accepted Date:

27 June 2017

Please cite this article as: Wilson, R.M., Tfaily, M.M., Rich, V.I., Keller, J.K., Bridgham, S.D., Medvedeff Zalman, C., Meredith, L., Hanson, P.J., Hines, M., Pfeifer-Meister, L., Saleska, S.R., Crill, P., Cooper, W.T., Chanton, J.P., Kostka, J.E., Hydrogenation of Organic Matter as a Terminal Electron Sink Sustains High $\mathrm{CO}_{2}: \mathrm{CH}_{4}$ Production Ratios During Anaerobic Decomposition, Organic Geochemistry (2017), doi: http://dx.doi.org/10.1016/ j.orggeochem.2017.06.011

This is a PDF file of an unedited manuscript that has been accepted for publication. As a service to our customers we are providing this early version of the manuscript. The manuscript will undergo copyediting, typesetting, and review of the resulting proof before it is published in its final form. Please note that during the production process errors may be discovered which could affect the content, and all legal disclaimers that apply to the journal pertain. 
Hydrogenation in anaerobic environments as an electron sink

Title: Hydrogenation of Organic Matter as a Terminal Electron Sink Sustains High $\mathrm{CO}_{2}: \mathrm{CH}_{4}$ Production Ratios During Anaerobic Decomposition

Author List: Rachel M. Wilson ${ }^{\mathrm{a}^{*}}$ and Malak M. Tfaily ${ }^{\mathrm{b}^{*}}$, Virginia I. Rich ${ }^{\mathrm{c}}$, Jason K. Keller ${ }^{\mathrm{d}}$, Scott D. Bridgham ${ }^{\mathrm{e}}$, Cassandra Medvedeff Zalman ${ }^{\mathrm{d}}$, Laura Meredith ${ }^{\mathrm{h}}$, Paul J. Hanson ${ }^{\mathrm{f}}$, Mark Hines ${ }^{\mathrm{g}}$, Laurel Pfeifer-Meister ${ }^{\mathrm{e}}$, Scott R. Saleska $^{\mathrm{h}}$, Patrick Crill ${ }^{\mathrm{i}}$, William T. Cooper ${ }^{\mathrm{j}}$, Jeff P. Chanton ${ }^{\mathrm{a}}$, and Joel E. Kostka ${ }^{\mathrm{k}}$

${ }^{a}$ Earth Ocean and Atmospheric Sciences, Florida State University, Tallahassee, FL 32306 USA

${ }^{\mathrm{b}}$ Environmental Molecular Sciences Laboratory_Pacific Northwest National Laboratory, Richland WA 99354 USA

${ }^{\mathrm{c}}$ Department of Microbiology, The Ohio State University, Columbus OH 43210 USA

${ }^{\mathrm{d}}$ Schmid College of Science and Technology, Chapman University, Orange, CA 92866 USA

${ }^{\mathrm{e}}$ Institute of Ecology and Evolution, University of Oregon, Eugene, OR 97403 USA

${ }^{\mathrm{f}}$ Oak Ridge National Laboratory, Oak Ridge, TN 37831 USA

${ }^{g}$ Department of Biological Sciences, University of Massachusetts, Lowell, MA USA

${ }^{\mathrm{h}}$ Department of Ecology and Evolutionary Biology, University of Arizona, Tucson, AZ 85721 USA

i Department of Geological Sciences, Stockholm University, SE-106 91 Stockholm, Sweden

${ }^{j}$ Department of Chemistry and Biochemistry Florida State University, Tallahassee, FL 32306 USA

${ }^{\mathrm{k}}$ Georgia Institute of Technology Atlanta, GA, 30332 USA

* authors Wilson and Tfaily contributed equally to this manuscript

${ }^{\ddagger}$ corresponding author email address: rmwilson @ fsu.edu, telephone +1 (850) 645-1887

\begin{abstract}
:
Once inorganic electron acceptors are depleted, organic matter in anoxic environments decomposes by hydrolysis, fermentation, and methanogenesis, requiring syntrophic interactions between microorganisms to achieve energetic favorability. In this classic anaerobic food chain, methanogenesis represents the terminal electron accepting (TEA) process, ultimately producing equimolar $\mathrm{CO}_{2}$ and $\mathrm{CH}_{4}$ for each molecule of organic matter degraded. However, $\mathrm{CO}_{2}: \mathrm{CH}_{4}$ production in Sphagnum-derived, mineral-poor, cellulosic peat often substantially exceeds this 1:1 ratio, even in the absence of measureable inorganic TEAs. Since the oxidation state of $\mathrm{C}$ in both cellulose-derived organic matter and acetate is $\mathbf{0}$, and $\mathrm{CO}_{2}$ has an oxidation state of +4 , if $\mathrm{CH}_{4}$ (oxidation state -4) is not produced in equal ratio, then some other compound(s) must balance $\mathrm{CO}_{2}$ production by receiving 4 electrons. Here we present evidence for ubiquitous hydrogenation of diverse unsaturated compounds that appear to serve as organic TEAs in peat, thereby providing the necessary electron balance to sustain $\mathrm{CO}_{2}: \mathbf{C H}_{4}>1$. While organic electron acceptors have previously been proposed to drive microbial respiration of organic matter through the reversible reduction of quinone moieties, the hydrogenation mechanism that we propose, by contrast, reduces $\mathrm{C}-\mathrm{C}$ double bonds in organic matter thereby serving as 1) a terminal electron sink, 2) a mechanism for degrading complex unsaturated organic molecules, 3) a potential mechanism to regenerate electron-accepting quinones, and, in some cases, 4) a means to alleviate the toxicity of unsaturated aromatic acids. This mechanism for $\mathrm{CO}_{2}$ generation without concomitant $\mathrm{CH}_{4}$ production has the potential to regulate the global warming potential of peatlands by elevating $\mathrm{CO}_{2}: \mathrm{CH}_{4}$ production ratios.
\end{abstract}

Keywords: anaerobic methanogenesis; $\mathrm{C}$ cycle; greenhouse gas; terminal electron acceptor; peatland; microbial respiration

\title{
Abbreviations
}

DOM - dissolved organic matter

FTICRMS - Fourier transform ion cyclotron resonance mass spectrometry

KMD-Kendrick mass defect

TEA - terminal electron acceptor

VFA - volatile fatty acid

Funding: this work was supported by the U.S. Department of Energy, Office of Science, Office of Biological and Environmental Research [grants: DE-AC05-00OR22725, DE-SC0004632, DESC0010580, DE-SC0012088 and DE-SC0014416]. 
Hydrogenation in anaerobic environments as an electron sink

\section{Introduction}

Over the past ten thousand years boreal peatlands have accumulated approximately $500 \mathrm{Gt}$ of carbon (C), an amount equal to half of the atmospheric $\mathrm{C}$ reservoir ( $\mathrm{Yu}$ 2012). This vast store of soil $\mathrm{C}$ could substantially impact the global $\mathrm{C}$ cycle if peatlands shift from net $\mathrm{C}$ sinks to net $\mathrm{C}$ sources. Peatlands act as $\mathrm{C}$ sinks by sequestering $\mathrm{CO}_{2}$ as organic $\mathrm{C}$ in deep anoxic peat (i.e., the catotelm). In the catotelm, cold temperatures, waterlogged conditions and the resultant lack of $\mathrm{O}_{2}$ all contribute to slow decomposition rates (Clymo, 1987). If these slow decomposition rates are the result of kinetic control—and not due to some inherent recalcitrance of the organic compounds themselves - then increased warming under changing climate conditions could stimulate the conversion of this organic matter to the respiration products $\mathrm{CO}_{2}$ and methane $\left(\mathrm{CH}_{4}\right)$, which could then be released back to the atmosphere creating a positive feedback to future warming. Since the sustained-flux global warming potential of $\mathrm{CH}_{4}$ is 45-times greater than that of $\mathrm{CO}_{2}$ on a $100 \mathrm{y}$ timescale (Neubauer and Megonigal 2015), the magnitude of this potential feedback will ultimately depend on the balance between net $\mathrm{CO}_{2}$ and $\mathrm{CH}_{4}$ emissions (Frolking et al. 2011).

Sphagnum-derived ombrotrophic peatland soils are low in mineral content and comprised mostly of cellulosic organic matter (Clymo 1987; Conrad 1999; Corbett et al. 2013). In the absence of a substantial mineral component, the traditional inorganic terminal electron acceptors (TEAs) for organic matter degradation are rapidly depleted or non-existent. For example, iron reduction and denitrification have been shown to be inconsequential in at least some ombrotrophic peat systems (Keller and Bridgham 2007) and nitrate, nitrite, and sulfate concentrations may be low or undetectable (Corbett et al. 2013; Hodgkins et al. unpublished). The majority of C stored in peatlands resides below the water table in the catotelm, where organic matter decomposition is dominated by fermentation reactions, syntrophy, and methanogenesis (Drake et al. 2009; Bridgham et al. 2013). These low-energy yielding reactions are only marginally thermodynamically favorable and depend on a delicately balanced syntrophic microbial consortium to break down organic molecules into $\mathrm{CO}_{2}$ and molecular hydrogen $\left(\mathrm{H}_{2}\right)($ Conrad 1999; Burdige 2006). The build-up of $\mathrm{H}_{2}$ in peat porewater resulting from this metabolic decomposition, however, inhibits the very fermentation processes that produce it (e.g. Lovley and Klug 1982). Thus, syntrophic reactions require a coupling reaction that consumes $\mathrm{H}_{2}$ in order to maintain electron flow and make the sum of the reactions energyyielding (Conrad 1999).

Hydrogenotrophic methanogenesis converts $\mathrm{CO}_{2}$ and $\mathrm{H}_{2}$ into $\mathrm{CH}_{4}$ thereby reducing $\mathrm{H}_{2}$ concentrations and yielding sufficient energy to make the overall syntrophic reactions thermodynamically favorable (Conrad 1999; Whiticar 1999):

$$
\mathrm{CO}_{2}+8 \mathrm{H}++8 \mathrm{e}^{-} \rightarrow \mathrm{CH}_{4}+2 \mathrm{H}_{2} \mathrm{O}
$$

In this reaction, the oxidation state of $\mathrm{C}$ goes from +4 to -4 thereby serving as an electron sink. This reaction is not a net sink for $\mathrm{CO}_{2}$, as $2 \mathrm{CO}_{2}$ are generated from 0 -valent organic matter to produce the hydrogen in the first place, as shown below (with sufficient reductant produced to then convert one $\mathrm{CO}_{2}$ to $\mathrm{CH}_{4}$ by Eq. (1)):

$$
2 \mathrm{CH}_{2} \mathrm{O}+2 \mathrm{H}_{2} \mathrm{O} \rightarrow 2 \mathrm{CO}_{2}+8 \mathrm{H}+8 \mathrm{e}^{-}
$$

The classic paradigm of cellulosic organic matter decomposition under anaerobic conditions assumes that, following the depletion of inorganic TEAs, hydrogenotrophic methanogenesis is the final $\mathrm{H}_{2}$ sink (Conrad 1999). 
Hydrogenation in anaerobic environments as an electron sink

While acetotrophic methanogenesis is also an important $\mathrm{CH}_{4}$ production pathway in peatlands, acetoclasty produces equimolar $\mathrm{CO}_{2}: \mathrm{CH}_{4}$ from 0 -valent acetate, and therefore does not present an electron imbalance.

Therefore, considering the breakdown of the model organic molecule as glucose (the monomer of which cellulose is constructed), electron balance would lead one to expect equimolar production of $\mathrm{CO}_{2}$ and $\mathrm{CH}_{4}$ as the net result in methanogenic cellulosic environments (Tarvin and Buswell 1934; Barker 1936; Schink 1997; Conrad 1999; Yavitt and Seidman-Zager 2006; Corbett et al. 2013).

$$
\mathrm{C}_{6} \mathrm{H}_{12} \mathrm{O}_{6} \rightarrow 3 \mathrm{CO}_{2}+3 \mathrm{CH}_{4}
$$

The overall $\mathrm{C}$ oxidation state in glucose is 0 , and Eq. (3) produces $3 \mathrm{CO}_{2}$ in which the $\mathrm{C}$ has an oxidation state of +4 , and $3 \mathrm{CH}_{4}$ where the oxidation state of $\mathrm{C}$ is -4 thereby preserving electron balance. When $\mathrm{CO}_{2}$ is produced without concomitant $\mathrm{CH}_{4}$ production, those 4 electrons must be transported to another sink. In mineral-rich settings, inorganic TEAs commonly serve that function allowing $\mathrm{CO}_{2}: \mathrm{CH}_{4}>1$, while many organic-rich anaerobic environments which are low in inorganic TEAs (such as lake sediments and landfills) conform to the predicted 1:1 $\mathrm{CO}_{2}: \mathrm{CH}_{4}$ production ratio (Lovley and Klug 1982; Tchobanoglous and Kreith 2002; Hines et al. 2008; Conrad et al. 2011). However, mineral-poor cellulosic peatlands - i.e. those dominated by Sphagnum — pose an exception (Yavitt and Seidmann-Zager, 2006; Hines et al. 2008; Nilsson and Öhlquist 2009). Despite a dearth of measurable inorganic TEAs in peat (e.g. Bridgham and Keller 2007; Corbett et al. 2013), measurements of $\mathrm{CO}_{2}: \mathrm{CH}_{4}$ production ratios in numerous field and incubation studies conducted across many different peatland sites have failed to demonstrate equimolar $\mathrm{CO}_{2}$ and $\mathrm{CH}_{4}$ production from deep (i.e., permanently saturated and anoxic) catotelm peat (Table 1; Valentine et al. 1994; Romanowicz et al. 1995; Updegraff et al. 1996; van Hulzen et al. 1999; Chasar et al. 2000a, b; Keller and Bridgham 2007; Wright et al. 2011; Corbett et al. 2013; McCalley et al. 2014; Hodgkins et al. 2014, 2015). $\mathrm{CO}_{2}$ production is much greater than expected in most cases resulting in a $\mathrm{CO}_{2}: \mathrm{CH}_{4}$ production ratio much greater than 1 .

While Sphagnum-derived peat is mineral-poor and composed primarily of cellulose (Clymo 1987; Corbett et al., 2013), a large fraction of the organic matter is comprised of aromatic and lignin-like molecules. Could the decomposition of such aromatic compounds account for the apparent $\mathrm{CO}_{2}: \mathrm{CH}_{4}$ imbalance? The earliest studies suggested that lignin was resistant to decomposition in the absence of $\mathrm{O}_{2}$ (Hackett et al. 1977; Zeikus et al. 1982; Odier and Monties 1983), but later work reported that limited anaerobic degradation of lignin is possible under some conditions - particularly in the presence of sulfate or nitrate as electron acceptors (Kaiser and Hanselmann, 1982; Benner et al. 1984; Colberg and Young 1985). However, very little was known about the mechanism of anaerobic decomposition of lignin-like compounds until recent studies demonstrated that the major lignin-derived aromatic compounds — syringate and vanillate — also produce equimolar $\mathrm{CO}_{2}: \mathrm{CH}_{4}$ under TEA-limited, methanogenic conditions (Kato et al. 2015). Thus, similar to cellulose, anaerobic decomposition of lignin-like aromatic compounds is expected to result in a $\mathrm{CO}_{2}: \mathrm{CH}_{4}$ near 1, and therefore the polyphenol content of peat cannot account for the observed non-stoichiometric production ratios.

Organic matter itself serves as an electron acceptor for microbial respiration in a variety of aquatic environments including peatlands, but the exact mechanism or extent to which this occurs is poorly understood (Lovley et al. 1996; Coates et al. 2002; Kappler et al. 2004; Keller et al. 2009; Roden et al. 2010; Smemo and Yavitt 
Hydrogenation in anaerobic environments as an electron sink

2011; Keller and Takagi 2013; Tfaily et al., 2013, 2014). Addition of humic acids to peat incubations drastically reduces methane production (Blodau and Deppe 2012). Both dissolved and solid-phase humic substances appear to have the ability to accept electrons, which has been proposed to account for elevated $\mathrm{CO}_{2}: \mathrm{CH}_{4}$ ratios (Scott et al., 1998; Heitmann and Blodau, 2006; Heitmann et al., 2007; Keller and Takagi, 2013). Quinone moieties are thought to act as the electron-accepting sites (Lovley et al., 1996; Kappler et al., 2004; Keller et al., 2009; Roden et al., 2010; Keller and Takagi 2013; Ye et al., 2016). However, quinone reduction is a reversible reaction similar to inorganic TEAs that requires re-oxidation to sustain high $\mathrm{CO}_{2}$ production rates, thus, this mechanism cannot fully explain persistently high $\mathrm{CO}_{2}: \mathrm{CH}_{4}$ production ratios in permanently saturated catotelm peat (Keller et al., 2009; Bridgham et al. 2013; Keller and Takagi 2013) and long-term, closed-system incubations (Bridgham et al. 2013) where no mechanism for reoxidation exists. Similarly, anaerobic oxidation of $\mathrm{CH}_{4}$ may occur to some extent at these sites and could result in $\mathrm{CO}_{2}: \mathrm{CH}_{4}>1$ (Smemo and Yavitt 2011; Gupta et al. 2012), but again an electron sink is required to accomplish this oxidation so we are left with the same problem - where are the electrons transferred? Further, stable $\mathrm{C}$ isotopic evidence does not support the amount of oxidation necessary to explain the observed excess $\mathrm{CO}_{2}$ in all sites (e.g. Corbett et al. 2013; Hodgkins et al. 2014).

Another mechanism that may explain an elevated $\mathrm{CO}_{2}: \mathrm{CH}_{4}$ ratio is fermentation. However, $\mathrm{CO}_{2}$ is not the only product of fermentation and we must account for the production of volatile fatty acids (e.g. acetate, butyrate, and propionate) and sometimes hydrogen resulting from fermentation if we are to accept this explanation. Acetate accumulation signals the inhibition of acetoclastic methane production which is associated with higher than expected $\mathrm{CO}_{2}: \mathrm{CH}_{4}$ ratios (Dudleston et al 2002; Hines et al., 2008), but acetate is not an electron sink since both acetate and glucose have an oxidation state of 0 and therefore acetate accumulation does not account for the electron imbalance imposed by high $\mathrm{CO}_{2}$ production. Homoacetogenesis, i.e. acetate formation via the Acetyl-CoA pathway, is a $\mathrm{H}_{2}$ sink in anoxic peat that could help draw down the $\mathrm{H}_{2}$ produced during fermentation. However, this reaction also consumes $\mathrm{CO}_{2}$ (Ye et al. 2014):

$$
2 \mathrm{CO}_{2}+8 \mathrm{H}++8 \mathrm{e}^{-} \rightarrow \mathrm{CH}_{3} \mathrm{COOH}+2 \mathrm{H}_{2} \mathrm{O}
$$

which would result in lower $\mathrm{CO}_{2}: \mathrm{CH}_{4}$ ratios than expected, not higher, and again acetate and glucose have the same oxidation state, so homoacetogenesis does not serve as a terminal electron sink. In addition, recent studies show that homoacetogenesis is outcompeted by other anaerobic processes in boreal and Arctic peatlands (Tveit et al., 2015; Schmidt et al., 2016).

Animal rumen are similar in many ways to peat soils. They are C-rich, devoid of inorganic electron acceptors, and the end products of fermentation (volatile fatty acids, $\mathrm{CO}_{2}$, and $\mathrm{CH}_{4}$ ) are slow to be removed suggesting that the ruminal system may be subject to similar thermodynamic limitation (Ungerfeld and Kohn 2006). In rumen, fermentation can be manipulated to increase propionate production. Since propionate has an oxidation state of -2 , there is no production of $\mathrm{H}_{2}$ and $\mathrm{CH}_{4}$ production is suppressed relative to fermentatitve acetate production thereby promoting elevated $\mathrm{CO}_{2}: \mathrm{CH}_{4}$ ratios (Mackie et al. 1984; Callaway and Martin 1996; Nagaraja et al. 2007). However, one difference from peatlands, is that, in rumen, the propionate (and acetate) can be absorbed by the 'host' animal for use in glandular metabolism. Thus propionate is removed from the rumen and does not accumulate. No such mechanism exists in peat, thus to sustain $\mathrm{CO}_{2}$ production by propionate production, propionate 
Hydrogenation in anaerobic environments as an electron sink

must either (1) accumulate in the peat, (2) be interconverted with succinate, or (3) be broken down into acetate with $\mathrm{H}_{2}$ as a byproduct. We do not always observe the build-up of propionate (or succinate) in peatlands where $\mathrm{CO}_{2}: \mathrm{CH}_{4}$ ratios are high (Hodgkins et al. 2014; McCalley et al. 2014; Wilson et al. unpublished), thus neither propionate nor succinate can be the final electron acceptor in these systems and interconversion with acetate without subsequent $\mathrm{CH}_{4}$ production would lead to excess $\mathrm{H}_{2}$.

Studies of the rumen system also point to another pathway in which organic matter may serve as an electron acceptor, namely the hydrogenation of aromatic double bonds. Biohydrogenation of double bonds is an important process in the rumen of cattle and sheep that is linked to a shunting of electrons away from methanogenesis (Rosenfeld and Tove, 1971; Kemp et al, 1975; Jenkins et al., 2007; McKain et al., 2010; Hristov et al., 2013) thereby suppressing $\mathrm{CH}_{4}$ production and sustaining elevated $\mathrm{CO}_{2}: \mathrm{CH}_{4}$ ratios (Nagaraja et al. 1997). Following ingestion, lipids are considerably altered in the rumen, and metabolomics analyses provide evidence that biohydrogenation reactions abound. For example, while the fatty acid profiles of lipids in cattle diet mostly contain unsaturated fatty acids, the lipids that exit the rumen are mostly saturated fatty acids (Jenkins et al. 2007). The rumen is a strictly anaerobic environment and hydrogenation of unsaturated hydrocarbons is thought to provide a selective advantage for microbial groups in the absence of inorganic electron acceptors (Kemp et al. 1975; McKain et al., 2010). Kemp et al. (1975) state that it is possible "that some anaerobes can use unsaturated fatty acids as a hydrogen sink, thus gaining a slight advantage over organisms not able to hydrogenate”. Any rumen microorganisms would also benefit from biohydrogenation through a reduction in toxicity, since unsaturated fatty acids are considered toxic and the reduction of their double bonds is thought to relieve their toxicity. Additionally, Hughes and Tove (1980) have suggested that the hydrogenation of double bonds in the rumen may regenerate quinones, which could provide a mechanism for sustaining $\mathrm{CO}_{2}$ production by ultimately receiving the electrons that are passed to quinone moieties thereby reoxidizing the quinones and allowing them to accept more electrons.

Studies of enrichment cultures and model anaerobes also point to organic electron accepting processes and the hydrogenation of double bonds. A number of bacterial cultures isolated from the rumen have been demonstrated to be capable of reducing aromatic acids, a process which involves hydrogenation (Krumholz and Bryant, 1986; Imkamp and Mueller, 2002). The metabolism of benzoyl-CoA, a key intermediate in nearly all known pathways for the microbial degradation of aromatic compounds, involves hydrogenation during the initial ring reduction (Fuchs et al., 2011; Meckenstock and Mouttaki, 2011; Porter and Young, 2014). Ring cleavage by addition of $\mathrm{H}_{2}$ is a nearly ubiquitous first step in the degradation of aromatic hydrocarbons under anaerobic conditions (Porter and Young 2014; Stenson et al. 2003). In a number of anaerobes (e.g., Wolinella succinogenes), fumarate respiration is coupled to hydrogen oxidation (i.e., $\mathrm{H}_{2}$ serves as the electron donor), and energy is produced through oxidative phosphorylation by hydrogenation of a double bond in fumarate (Kroger et al., 2002).

Microbial growth could elevate the $\mathrm{CO}_{2}: \mathrm{CH}_{4}$ ratio as microbial biomass is largely composed of compounds that are reduced relative to cellulose (Hungate et al., 1961; Nilsson and Öquist 2009). This is considered to be an important mechanism maintaining non-stoichiometric $\mathrm{CH}_{4}$ production in rumen (Hungate et al. 1961). While peatlands share many similarities with anaerobic digestion in rumen, there yet remain some important differences. The rumen acts more like a (near) constant addition flow through reactor as fresh readily fermentated carbohydrates 
Hydrogenation in anaerobic environments as an electron sink

are added to the milieu at least daily, volatile acid fermentation products are absorbed by the ruminant cells for glandular metabolism thereby removing them from the system (Nagaraja et al. 1997) and microbial cells and other products are lost from the gut. In both rumen and peatlands, the turnover of microbial biomass releases the reduced compounds (e.g. lipids and proteins) back into the DOM pool. Decomposition of proteins and lipids which generally have a lower oxidation state than carbohydrate, would shift production towards more $\mathrm{CH}_{4}$ than $\mathrm{CO}_{2}$ (Nilsson and Öquist 2009). Thus the influence of microbial growth on elevating $\mathrm{CO}_{2}: \mathrm{CH}_{4}$ ratios is likely much stronger in rumen than in peatlands which are comparatively more stable and presumably microbial biomass is closer to a dynamic equilibrium.

The goal of this study was to examine the potential for biohydrogenation of organic matter to serve as an electron sink capable of sustaining $\mathrm{CO}_{2}$ production in peatlands without concomitant $\mathrm{CH}_{4}$ production. To accomplish this goal we used Fourier transform ion cyclotron resonance mass spectrometry (FTICRMS) followed by Kendrick mass transform analysis to investigate molecular changes in the dissolved organic matter (DOM) of two northern peatlands. The Kendrick mass (i.e., Kendrick 1963) transform analysis identifies gain or loss of specific chemical moieties (e.g. $\mathrm{CH}_{2}, \mathrm{H}_{2}, \mathrm{CH}_{2} \mathrm{O}$, etc) via mass differences, and was used to infer potential microbial degradation pathways by which compounds were consumed in these samples. We examined peat chemistry from two boreal peatlands (with different cryogenic histories) at multiple depths in the field and over time in incubations, in tandem with measurements of $\mathrm{CO}_{2}: \mathrm{CH}_{4}$ production ratios.

\section{Material and methods}

For field comparisons, porewater was collected from the S1 bog, a Sphagnum-dominated site at northern Minnesota peatland in the Marcell Experimental Forest $\left(47.51911^{\circ} \mathrm{N}, 93.45964^{\circ} \mathrm{W}\right.$, USA) using permanentlyinstalled piezometers, which provided profiles from the watertable surface to $200 \mathrm{~cm}$ depth. Porewater was also collected from an additional Sphagnum-dominated site within Stordalen Mire (68.350 $\mathrm{N}, 19.033^{\circ} \mathrm{E}$, Sweden), a palsa mire underlain by thawing permafrost, using perforated stainless steel tubes that were inserted into the peat to the desired depths $(13 \mathrm{~cm}$ and $32 \mathrm{~cm}$ ). Porewater was immediately filtered to $0.7 \mu \mathrm{m}$ in the field at both sites using Whatman glass fiber filters then stored in polycarbonate vials and frozen for shipment. Volatile fatty acid (VFA) analysis was conducted following the methods of Hines et al. (2008). Acetate, propionate, and butyrate concentrations in filtered pore water were determined using a Dionex ICS-2100 Reagent-Free ion chromatograph (Thermo Scientific) fitted with an AS11-HC column, EGC III Potassium Hydroxide eluent generator, and ASRS 300 suppressor. Standards were prepared using sodium acetate, propionic acid, and sodium butyrate, respectively. Samples were neutralized using $0.1 \mathrm{M}$ sodium hydroxide prior to analysis and run in duplicate (relative standard deviation < 5\%) using a hydroxide gradient from $1 \mathrm{mM}$ to $50 \mathrm{mM}$ for optimal peak separation. Level of detection for VFA analysis was $0.1 \mathrm{mg} / \mathrm{L}$.

Anaerobic incubation studies were conducted on peat from 8-18 cm deep collected from Stordalen Mire following the procedures of Hoddgkins et al. $(2014,2015)$. This depth was chosen as the shallowest permanently inundated depth at that site. The peat was gently homogenized by gloved hands using a pulling-shredding motion to adequately homogenize the sample while maintaining the integrity of the peat. Peat was aliquoted into six $125 \mathrm{~mL}$ 
Hydrogenation in anaerobic environments as an electron sink

serum vials ( $40 \mathrm{~g}$ each) to which we added $40 \mathrm{~mL}$ of degassed deionized water and then capped. The vials were flushed with $\mathrm{N}_{2}$ gas and shaken gently until $\mathrm{CO}_{2}$ concentrations in the headspace were below $0.1 \%$ as measured by flame ionization gas chromatography with use of a methanizer. The sealed vials were then stored in the dark at ambient room temperature $\left(18-22^{\circ} \mathrm{C}\right)$ for a 25 -day pre-incubation period to equilibrate the samples and consume any oxygen that was inadvertently introduced during the setup and reduce any inorganic TEAs that might have been present (e.g. Hodgkins et al. 2014, 2015). At the end of this pre-incubation period, vials were flushed with $\mathrm{N}_{2}$ and shaken again, until a final $\mathrm{CO}_{2}$ concentration $<0.1 \%$ and $\mathrm{CH}_{4}$ concentration $<0.5 \%$ was attained in the headspace. At this point, two vials were sacrificed for the 'day 0' porewater sampling. Porewater was removed and filtered to $0.2 \mu \mathrm{m}$ to remove cells. The remaining vials were stored undisturbed in a dark, room-temperature location for 50 days. Periodically, $50-150 \mu \mathrm{L}$ of the headspace was removed to monitor the concentration and isotopic ratio $\left(\delta^{13} \mathrm{C} \%\right.$ o) of the produced $\mathrm{CO}_{2}$ and $\mathrm{CH}_{4}$ by isotope ratio mass spectrometry. At the end of 50 days, two additional replicates were sacrificed for the 'day 50' porewater analysis. Again the porewater was filtered to $0.2 \mu \mathrm{m}$ then frozen.

Thawed porewater samples were mixed with 2 parts methanol for direct injection on a 12T Bruker SolariX Fourier transform ion cyclotron ratio mass spectrometer (FTICRMS) at the Environmental Molecular Sciences Laboratory, a national user facility (Richland, WA, USA). A standard Bruker ESI source was used to generate negatively charged molecular ions. Samples were then introduced to the ESI source equipped with a fused silica tube ( $200 \mu \mathrm{m}$ i.d) through a syringe pump at a flow rate of $3.0 \mu \mathrm{L} / \mathrm{min}$. Experimental conditions were as follows: needle voltage, $+4.4 \mathrm{kV}$; Q1 set to $150 \mathrm{~m} / \mathrm{z}$; and the heated resistively coated glass capillary operated at $180^{\circ} \mathrm{C}$. Ninety-six individual scans were averaged for each sample and internally calibrated using organic matter homologous series separated by $14 \mathrm{Da}\left(-\mathrm{CH}_{2}\right.$ groups). The mass measurement accuracy was typically less than 1 ppm for singly charged ions across a broad $\mathrm{m} / \mathrm{z}$ range (i.e. $200,<\mathrm{m} / \mathrm{z}<1200$ ). Chemical formulas were assigned using an in-house built software program following the Compound Identification Algorithm, described by Kujawinski and Behn (2006) and modified by Minor and Stephens (2008). Chemical formulas were assigned based on the following criteria: $\mathrm{S} / \mathrm{N}>7$, and mass measurement error $<1 \mathrm{ppm}$, taking into consideration the presence of $\mathrm{C}$, $\mathrm{H}, \mathrm{O}, \mathrm{N}, \mathrm{S}$ and $\mathrm{P}$ and excluding other elements. All observed ions in the spectra were singly charged as confirmed by the $1.0034 \mathrm{Da}$ spacing found between isotopic forms of the same molecule (between ${ }^{12} \mathrm{C}_{\mathrm{n}}$ and ${ }^{12} \mathrm{C}_{\mathrm{n}-1}-{ }^{13} \mathrm{C}_{1}$ ). In terms of overall coverage, we were able to assign $>85 \%$ of the peaks observed in each spectrum. Duplicate injections were run for the Sweden field samples with $80 \%$ of peaks replicated in both analysis runs. Methanol was also analyzed as a blank. Forty peaks appeared in the methanol and were subtracted from the samples. Only peaks appearing in all instrument and method replicates for each sample were considered in further analyses.

Peaks were divided into two categories: 'consumed' and potential 'end products'. For the field data, compounds that appeared in shallower samples but were missing from deeper samples (up to $200 \mathrm{~cm}$ and $32 \mathrm{~cm}$ for Minnesota and Sweden respectively) were considered to have been "consumed" while all compounds present in the deep samples were considered potential "end products", regardless of their appearance elsewhere. The vertical progression of peat decomposition has been confirmed in these (Tfaily et al., 2014; Hodgkins et al., 2014, 2015) and other peatland ecosystems (Tfaily et al. 2013). Similarly in the incubations, peaks that were detected at the 
Hydrogenation in anaerobic environments as an electron sink

beginning of the incubation (day 0) but disappeared by the end of the incubation (day 50) were considered to have been "consumed" during the course of the incubations. Compounds that were present at day 50 were considered potential "end products" regardless of their appearance elsewhere. The total number of peaks detected in each sample as well as the number of consumed compounds for each depth in the field or sampling time in the incubations are provided in SI Table 1.

Kendrick mass analysis involves mathematically transforming the data to alternate mass scales through the use of conversion factors that set the mass of a desired chemical moiety to an integer atomic mass value (sensu Kendrick 1963). The Kendrick mass defect (KMD) is defined as the difference between the resulting exact and nominal masses. In the newly calculated masses, peaks that have identical KMD have molecular formulae that differ by integer multiples of the chemical moiety (transform) investigated. The Kendrick mass (KM) of a peak is determined by: $\mathrm{KM}=$ observed mass $\times \frac{F_{\text {nominal_mass }}}{F_{\text {exact_mass }}}$ where $\mathrm{F}$ is the transform of interest. We applied Kendrick mass transforms to the samples based on a list of 162 transforms assembled from the literature (SI Table 2) that represented potential microbial decomposition strategies. To further constrain our data we also calculated $\mathrm{z}^{*}$ scores for each peak (sensu Hsu et al. 1992). This score, which is calculated as the modulus of the division of the peak nominal mass by $\mathrm{F}_{\text {nominal_mass, }}$ ensures that compounds with the same $\mathrm{z}^{*}$ score have molecular weight differences consistent with the transform of interest and reduces the number of false KMD matches due to measurement errors (Hsu et al. 1992; Stenson et al. 2003). The KMDs of 'consumed' peaks were compared to 'end product' peaks to identify potential pathways by which the consumed peaks may have been degraded. When a consumed peak and an end product peak had KMD values within 0.000001 mass units and an identical $z^{*}$ score, those peaks were counted as a transform pair and it was assumed that the consumed peak was degraded to the end product peak by the relevant transform. For each of the 162 transforms that we investigated, we counted the total number of such transform pairs in each sample and present them as the fraction of the total number of consumed peaks present in the samples (Fig. 2). It is important to note that a single peak can be involved in multiple transforms, from which we infer that there are different pathways by which it can be degraded. Thus, the sum of the transform counts could be somewhat greater than the sum of consumed compounds. By mass comparison, we noted whether the consumed compound was transformed by addition or removal of the relevant chemical moiety.

\section{Results}

In our incubations of Stordalen Mire peat, $\mathrm{CO}_{2}$ and $\mathrm{CH}_{4}$ concentrations increased linearly throughout the incubation period (Fig. 1a). The $\mathrm{CO}_{2}: \mathrm{CH}_{4}$ ratio in the incubations remained fairly stable from day 8 through day 50, approaching a value of $\sim 1.5$ (Fig. 1b), these results are in agreement with observations made by Hodgkins et al., (2014) at this same Stordalen Mire site. For comparison, previous incubations of peat from S1 bog yielded $\mathrm{CO}_{2}: \mathrm{CH}_{4}$ ratios that varied from 2 to 100 , and increased as a function of depth (Tfaily et al., 2014).

In the Stordalen Mire bog field samples, the concentrations of VFA's that serve as electron sinks - butyrate and propionate - were maintained at very low levels ( $<10 \mu \mathrm{M}$ and $<0.1 \mu \mathrm{M}$ respectively measured from $12 \mathrm{~cm}$ to 70 cm deep) (Hodgkins et al., 2014; McCalley et al., 2014). Electron harboring VFA concentrations at S1 bog in Minnesota are similarly low—propionate averaged $2.3 \pm 7.5 \mu \mathrm{M}$ and butyrate averaged $0.4 \pm 1.3 \mu \mathrm{M}$. 
Hydrogenation in anaerobic environments as an electron sink

The Kendrick mass (i.e., Kendrick 1963) transform analysis identifies gain or loss of specific chemical moieties (e.g. $\mathrm{CH}_{2}, \mathrm{H}_{2}, \mathrm{CH}_{2} \mathrm{O}$, etc) via mass differences, and was used to infer potential microbial degradation pathways by which compounds were consumed in these samples. This is an environmental analogue to "traditional" small-molecule metabolomics, in which small molecule metabolites are used to identify cellular processes. Environmental metabolomics differs in its complexity and molecule size; it is not a set of well-defined chemical fingerprints, but rather the entire DOM pool. Microbial processes are encoded in the changes in DOM pool composition (e.g. over time) rather than appearance/disappearance of specific metabolites.

The most commonly occurring transform in the field samples from both peatlands was the addition of 2 hydrogens. We will write this transform ambiguously as $+2[\mathrm{H}]$ recognizing that when $\mathrm{H}_{2}$ is not the direct electron donor, nevertheless, metabolic hydrogen is in equilibrium with aqueous $\mathrm{H}_{2}$ (Ungerfeld and Kohn 2006). In either case, transform results indicate that hydrogenation was an important step in the transformation of DOM in these systems (Fig. 2) accounting for $\sim 3.5-5 \%$ of the transforms observed in field samples. Similarly, $+2[\mathrm{H}]$ was the second-most commonly occurring transform in the incubations, accounting for $\sim 2 \%$ of the total number of transforms. The most commonly occurring transform in the incubations was $\mathrm{CH}_{4}$ exchange for $\mathrm{O}_{2}$, which could represent the accumulation of multiple smaller transforms and closely matches reactions for degrading lignin in which 2[H]'s are removed from side chains, followed by demethylation, and aromatic ring cleavage by addition of $\mathrm{O}_{2}$ (e.g., Stenson et al. 2003). Thus hydrogenation and dehydrogenation appear to be simultaneously occurring reactions important in the degradation of organic matter.

FT-ICR MS analysis allows inferences about some of the chemical characteristics of the compounds undergoing these transforms to be examined. A diversity of consumed compounds across both field and incubation data were linked by the hydrogenation transform (Fig. 3). In total, we identified 216 unique organic compounds that were transformed by the addition of $2[\mathrm{H}]$ (given that the later incubation time points show addition relative to earlier time points, and that deeper catotelm samples show addition relative to shallower ones). These compounds spanned most of the overall DOM pool's O/C vs H/C space, and represented a range of degree of oxidation, double bond equivalences, and heteroatom (N,S,P) contents (Fig. 3). While in general higher molecular weight, heteroatomsubstituted compounds appear less susceptible to the $+2[\mathrm{H}]$ consumption mechanism, overall, the potential substrates of the $+2[\mathrm{H}]$ transform appeared numerous and chemically diverse.

\section{Discussion}

Our results suggest that, as in the rumen, hydrogenation of unsaturated organic matter in peatlands not only serves as a requisite for the degradation of these compounds, but also as a terminal electron sink, sustaining fermentation without subsequent $\mathrm{CH}_{4}$ generation and possibly reducing $\mathrm{H}_{2}$ production, thereby explaining the nonstoichiometric production of $\mathrm{CO}_{2}$ relative to $\mathrm{CH}_{4}$. The parallels between the rumen and peatlands are striking. In the rumen, the addition of tannins and saponins have been specifically used to inhibit the production of $\mathrm{CH}_{4}(\mathrm{Hristov}$ et al. 2014). In peatlands, when dissolved humic acids are added to incubations, methanogenesis is similarly curtailed (Blodau and Deppe, 2012). 
Hydrogenation in anaerobic environments as an electron sink

Hydrogenation of C-C double bonds is involved in the degradation of complex unsaturated organic molecules and may be a strategy to reduce the toxicity of aromatic acids released during the decomposition of plant organic matter (Rosenfeld and Tove 1971; Chesson et al. 1982). Sphagnum-dominated peatlands, as well as other anaerobic ecosystems, contain an abundance of plant-derived aromatic acids (e.g., cinnamic, vanillic, syringic, caffeic, ferulic acid) (Williams et al., 1998). In fact, the highly unsaturated sphagnic acid (p-hydroxy-B[carboxymethyl]-cinnamic acid) is among the most abundant degradation products of Sphagnum litter and is thought to inhibit decomposition in Sphagnum-dominated bogs (Rudolph and Samland, 1985; Williams et al., 1998). Because hydrogenation of C-C double-bonds also represents an electron sink, this mechanism could be important both for alleviating toxicity and as an electron sink to sustain microbial respiration of cellulosic material. Addition of $2[\mathrm{H}]$ across a $\mathrm{C}-\mathrm{C}$ double bond changes the $\mathrm{C}$ oxidation state by -1 , i.e., the reduction of the double bond is electron accepting. Thus, reduction of unsaturated organic compounds acts as an electron and putative molecular hydrogen sink allowing $\mathrm{CO}_{2}$ production without subsequent $\mathrm{CH}_{4}$ generation. However, because metabolic hydrogen is in equilibrium with $\mathrm{H}_{2 \text { (aq) }}$ (Ungerfeld and Kohn 2006), it may be that the biohydrogenation of double bonds serves as an alternative electron sink bypassing proton reduction which simply results in suppressing the formation of $\mathrm{H}_{2}$.

The first phase of decomposition in anaerobic environments where inorganic TEAs other than $\mathrm{CO}_{2}$ are not available has been dubbed the "acid phase", in which fermentation produces fatty acids, alcohols, $\mathrm{CO}_{2}$ and $\mathrm{H}_{2}$ (Conrad 1999; Tchobanoglous and Kreith 2002). The predominant fermentation intermediates in peatland soils all represent potential electron sinks (with the exception of acetate as discussed in the introduction) (Tveit et al., 2015; Schmidt et al., 2015; 2016). Syntrophic bacteria then further degrade the alcohols and fatty acids to acetate or formate, $\mathrm{CO}_{2}$ and $\mathrm{H}_{2}$. In the commercial production of volatile fatty acids (VFAs) in anaerobic digesters, conditions are manipulated to maintain the system in the acid production phase. This is sometimes accomplished by addition of fresh organic matter substrate (e.g., Pervin et al. 2013; Vanwonterghem et al. 2015), which serves to overcome the thermodynamic constraints to $\mathrm{H}_{2}$ production by increasing the concentration of the reactants (Ungerfeld and Kohn 2006) thereby driving the reaction towards VFA $+\mathrm{H}_{2}$ production (Burdige 2006). In anaerobic incubations and in peatlands where fresh organic matter enters the anaerobic zone slowly or not at all, the acid production phase occurs very early in diagenesis. Then, if $\mathrm{H}_{2}$ concentrations build up faster than organic matter is added, VFA concentrations increase, and an $\mathrm{H}_{2}$ sink is required to allow syntrophic reactions to continue (Conrad 1999; Tchobanoglous and Kreith 2002). For example, at Stordalen Mire, the concentrations of VFAs build up only in the early-stage permafrost thaw habitats, but in the bog habitat examined in this study — which is a more mature thaw feature (Hodgkins et al., 2014; McCalley et al., 2014) - fermentation products such as acetate are maintained at very low levels ( $<10 \mu \mathrm{M}$ and $<0.1 \mu \mathrm{M}$ respectively measured from $12 \mathrm{~cm}$ to $70 \mathrm{~cm}$ deep) or are below detection (butyrate and propionate). Concentrations of VFA's with reduced oxidation states at the Minnesota bog site are similarly low—propionate averaged $2.3 \pm 7.5 \mu \mathrm{M}$ and butyrate averaged $0.4 \pm 1.3 \mu \mathrm{M}$ —indicating that at the sites investigated in this study, fermentation is coupled to VFA consuming reactions which require concomitant $\mathrm{H}_{2}$ consuming reactions to be thermodynamically favorable.

Much of the anaerobic food chain and electron flow pathways in peatlands remain as a "black box", with the majority of studies of fermentation and syntrophy conducted in the laboratory (Schmidt et al., 2016). However, a 
Hydrogenation in anaerobic environments as an electron sink

growing body of microbiological evidence from the laboratory and field corroborates our environmental metabolomics results pointing to unsaturated organic compounds as an electron sink and possibly an $\mathrm{H}_{2}$ sink. Nearly all microbial groups detected in abundance in freshwater wetland soils under anaerobic conditions have been shown to be capable of the fermentation or respiration of aromatic compounds (Schink and Stams, 2006; Sieber et al., 2012). Acetogens and other syntrophs, sulfate-reducers, and metal-reducers were all shown to respire organic electron acceptors such as fumarate in pure culture (Sieber et al., 2012). Fumarate reduction involves hydrogenation of a double bond to produce succinate (Kroger et al., 2002). Of these groups, classic syntrophs (Syntrophococcus, Clostridium) and acetogens (Acetobacterium) are capable of the fermentation or respiration of aromatic acids as the sole electron acceptor (Bache and Pfennig, 1981; Tschech and Pfennig, 1984; Krumholz and Bryant, 1986; Imkamp and Muller, 2002).

Microbiological studies from the S1 bog in Minnesota and from Stordalen Mire in Sweden corroborate environmental metabolomics results from the field. The most abundant microbial taxa detected in the anaerobic catotelm of the S1 bog are groups which are capable of utilizing organic electron acceptors, particularly fumarate (Lin et al., 2014a,b; 2015). A combination of amplicon sequencing and metagenomics data showed that novel members of the Thaumarchaeota, which are among the most abundant taxa in the S1 catotelm, are syntrophic and capable of fumurate respiration (Lin et al., 2014a; 2015). In that study, members of the Syntrophobacterales and Geobacter groups increased in the catotelm of S1 bog where our transform data indicate hydrogenation of organic matter is important. These groups which mediate fermentation, syntrophy, and utilize fumarate as the sole electron acceptor by direct interspecies electron transfer (Sieber et al., 2012; Wang et al., 2016) are also prevalent at Stordalen Mire (Mondav and Woodcroft et al. 2014, supplemental data). Furthermore, Tfaily et al. (2015) identified a unique fluorescent chromophore in pore waters from the nearby Glacial Lake Agassiz peatlands in Minnesota that appeared to be a microbial by-product originating from humic matter, consistent with the microbial transformation of unsaturated compounds. Increasing alkylation of dissolved organic matter with increasing depth was also observed in the Glacial Lake Agassiz peatlands which is consistent with our hypothesis of increasing hydrogenation of organic matter (Tfaily et al,, 2013).

Mechanistically, the FTICRMS results only show that an addition of 2 hydrogens is occurring; we cannot be certain that molecular hydrogen, $\mathrm{H}_{2}$, is being consumed in these reactions. Tracer studies in the rumen with labeled $\mathrm{H}$ in water, glucose, formate and succinate have indicated the $\mathrm{H}$ from these organic molecules does not come from molecular $\mathrm{H}_{2}$ added across the double bond to saturate it, but rather the $\mathrm{H}$ that is added comes from water which acts as a shuttle accepting and donating hydrogens. These studies indicate the addition of a proton and a hydride ion with NADH serving as an electron donor (Rosenfeld and Tove 1971; Jenkins et al. 2007). These authors clearly state, however, that their results do not "preclude the direct reduction of a carrier by an organic substrate if the hydrogen undergoes rapid exchange with water". Similarly in hydrogenotrophic methanogenesis (Eq. (1)), during the hydrogenation of $\mathrm{CO}_{2}$ to form $\mathrm{CH}_{4}$-which is often written as a reduction of $\mathrm{H}_{2}: \mathrm{CO}_{2}+4 \mathrm{H}_{2} \rightarrow \mathrm{CH}_{4}+$ $2 \mathrm{H}_{2} \mathrm{O}$ - the $\mathrm{H}$ is apparently actually derived from or is at least in isotopic equilibrium with water (Whiticar et al., 1986; Waldron et al., 1999; Whiticar 1999; Chanton et al., 2006). Thus it remains unclear in all of these 
Hydrogenation in anaerobic environments as an electron sink

transformations whether $\mathrm{H}_{2}$ itself is reduced during the hydrogenation step or whether the actual hydrogen comes from another source (e.g., water) with organic matter supplying the electrons.

The diversity of the hydrogenation process - where $\mathrm{H}_{2}$ is used as the electron carrier - and its widespread distribution is supported by the recent discovery of hydrogenase genes in 51 bacterial and archaeal phyla that are ubiquitous in aquatic and terrestrial habitats (Greening et al. 2015). Hydrogenases actively catalyze $\mathrm{H}_{2} / \mathrm{H}_{2} \mathrm{O}$ exchange in addition to catalyzing reversible reactions with $\mathrm{H}_{2}$ as reactant or product (Vogt et al., 2008). Greening et al. (2015) note that $\mathrm{H}_{2}$ was the first electron donor for life, and that the great diversification of hydrogenases may have allowed the growth and survival of microbiota across many ecosystems. Thus it seems plausible that $\mathrm{H}_{2}$ could be the electron carrier for the hydrogenation mechanism identified in this study. In any case, metabolic hydrogen is in equilibrium with $\mathrm{H}_{2(\mathrm{aq})}$ and thus the implications for the thermodynamics of the system are the same whether $\mathrm{H}_{2}$ is the direct participant or not (Ungerfeld and Kohn 2006).

As described above, organic matter has previously been proposed as a potential electron acceptor for microbial respiration in a variety of aquatic environments including peatlands (Lovley et al. 1996; Coates et al. 2002; Kappler et al. 2004; Keller et al. 2009; Roden et al. 2010; Smemo and Yavitt 2011; Keller and Takagi 2013). While previous evidence pointed to the potential for quinone moieties to serve as the active electron accepting site (Lovley et al., 1996; Kappler et al., 2004; Keller et al., 2009; Roden et al., 2010; Blodau and Deppe 2012; Keller and Takagi 2013) quinone reduction is a reversible reaction that requires reoxidation to sustain high $\mathrm{CO}_{2}$ production rates. The prevalence of the $+2[\mathrm{H}]$ reaction in both the field and incubation samples, and the diversity of substrates consumed by this mechanism (Fig. 3), supports the idea that reduction of C-C double bonds can serve as an abundant hydrogen sink and TEA. Unlike other TEAs which are quickly depleted in the shallow subsurface, this electron sink may indeed be quite large, less easily depleted, and therefore able to sustain prolonged secondary fermentation associated with the breakdown of the large peatland organic matter pool, leading to sustained high $\mathrm{CO}_{2}$ production. The hydrogenation reaction may additionally serve to reoxidize quinones or other TEAs replenishing their electron accepting capabilities (Nilsson and Öquist 2009). Furthermore, observations of modern $\mathrm{C}$ fueling $\mathrm{CO}_{2}$ and $\mathrm{CH}_{4}$ production in deep peat (Chanton et al., 2008; Corbett et al., 2013; Wilson et al. 2016) suggest that downward advection of DOM through the peat column may refresh organic $\mathrm{C}$ stores enhancing their ability to act as a large electron sink in the catotelm.

Because $\mathrm{CH}_{4}$ has a sustained flux global warming potential approximately 45 times that of $\mathrm{CO}_{2}$ on the 100y timescale (Neubauer and Megonigal 2015), the ratio of $\mathrm{CO}_{2}: \mathrm{CH}_{4}$ emissions from peatlands has far-reaching implications for understanding the role that these systems play in future climate change. As peatlands thaw, mechanisms, such as the one proposed in this paper which have the potential to control $\mathrm{CO}_{2}: \mathrm{CH}_{4}$ emission ratios, will become increasingly pertinent to global climate modeling efforts.

This proposed mechanism does not preclude the involvement of quinone moieties as intermediate electron acceptors in catotelm peat, however. In fact, it is entirely possible that quinone reduction could be a mechanism of electron transport and would be consistent with previous evidence of quinone reduction in such systems (Roden et al. 2010; Keller and Takagi 2013, etc). We suggest that quinone reduction does not represent a terminal electron accepting step, however. As indicated by Hughes and Tove (1980) reduced quinones (quinols) could be regenerated 
Hydrogenation in anaerobic environments as an electron sink

by reducing $\mathrm{C}-\mathrm{C}$ double bonds in organic matter, thereby themselves being re-oxidized and becoming available for further electron shuttling capabilities (Keller and Bridgham, 2007; Keller et al., 2009). The hydrogenation step we propose could be a mechanism for reoxidizing quinones or small quantities of other TEAs thereby sustaining their electron accepting capabilities (e.g. Nilsson and Öquist 2009).

Because the potential pool of unsaturated $\mathrm{C}$ compounds is large, such quinone recycling has the potential to be a significant control on the ratio of $\mathrm{CO}_{2}$ to $\mathrm{CH}_{4}$ produced during anaerobic decomposition in peatlands and appears to be rapidly renewed with downward vertical advection of surface DOM. The hydrogenation mechanism proposed in this study therefore links microbial respiration with the reduction of large (150-700 Da) ubiquitous unsaturated organic compounds and has the potential to control long-term $\mathrm{CO}_{2}: \mathrm{CH}_{4}$ emission dynamics from peatlands by promoting $\mathrm{CO}_{2}$ over $\mathrm{CH}_{4}$ production while serving as an electron sink.

Further support that the proposed hydrogenation mechanism can be used to explain the $\mathrm{CO}_{2}: \mathrm{CH}_{4}$ imbalance could be garnered from a quantitative mass balance. Unfortunately, FTICRMS is currently not a quantitative technique thus such a mass balance is currently unavailable. Future work should focus on improving the quantification of the hydrogenation transform to determine whether or how much of the $\mathrm{CO}_{2}: \mathrm{CH}_{4}$ imbalance could potentially be explained by this mechanism.

Thus far we have limited our investigation to the dissolved organic matter pool, however, the solid phase peat itself represents an even larger reservoir of organic $\mathrm{C}$ that may also have the potential to act as an electron sink (Roden et al., 2010; Keller and Takagi, 2013). Application of the FTICRMS technique to strictly solid phase samples is still under development and quantification of this and the DOM electron sinks will, in part, require identification of those compounds that are most susceptible to $+2[\mathrm{H}]$ addition. However, results of our previous analyses of these and other peatland sites over more than a decade have indicated that $\mathrm{CO}_{2}$ and $\mathrm{CH}_{4}$ production in these systems are more strongly influenced by DOM than solid phase organic C dynamics (Wilson et al., 2016; Tfaily et al. 2014; Corbett et al. 2013, Chanton et al. 2008; Chasar et al. 2000a) thus we feel that our focus on the DOM in this study is highly relavent to understanding the $\mathrm{CO}_{2}: \mathrm{CH}_{4}$ production dynamics.

It is possible that fluctuating water table depths could transiently expose peat within the mesotelm to $\mathrm{O}_{2}$ changing redox conditions and reoxidizing TEAs that were previously reduced, recycling them for further oxidation and sustaining microbial respiration (Bridgham et al. 2013). Such a mechanism could allow sulfate or iron reduction in spite of very low measured concentrations of these potential TEAs by rapid turnover (Keller and Bridgham 2007). However, the field samples collected from Stordalen Mire were taken from below the mesotelm of peat that is permanently inundanted and the closed incubations were highly anaerobic with little chance of changing redox conditions. Thus reoxiddation events are unlikely to be influencing our present results and explaining the elevated $\mathrm{CO}_{2}: \mathrm{CH}_{4}$ observed in these samples.

FTICRMS environmental metabolomics data in this study combined with the metagenomics results together suggest a new view of peatland anaerobic decomposition, in which organic electron acceptors, that potentially scavenge $\mathrm{H}_{2}$ and maintain electron flow in boreal peatlands, regulate the $\mathrm{CO}_{2}: \mathrm{CH}_{4}$ production ratio in these systems (e.g., Blodau and Deppe 2012). This mechanism challenges the conventional understanding of controls on $\mathrm{CO}_{2}: \mathrm{CH}_{4}$ production in TEA-depleted environments by explaining the sustained breakdown of organic 
Hydrogenation in anaerobic environments as an electron sink

matter to $\mathrm{CO}_{2}$ without concomitant $\mathrm{CH}_{4}$ production. This work, thus, provides an important step in understanding the greenhouse gas balance of these systems and the microbial and thermodynamic determinants of feedbacks that may play an important role in future climate change.

Data Availability Data are available publicly from the Carbon Dioxide Information Analysis Center, Oak Ridge National Laboratory, U.S. Department of Energy, Oak Ridge, TN U.S.A. at: DOI pending.

The authors declare that they have no conflict of interest.

\section{Acknowledgements}

This material is based upon work supported by the U.S. Department of Energy, Office of Science, Office of Biological and Environmental Research. Oak Ridge National Laboratory is managed by UT-Battelle, LLC, for the U.S. Department of Energy under contract DE-AC05-00OR22725. Work in Sweden was funded by the US Department of Energy Office of Biological and Environmental Research under the Genomic Science program (Awards DE-SC0004632 and DESC0010580). Work in Minnesota was supported by the Terrestrial Ecosystem Science (TES) Program, under U.S. Department of Energy contracts \# DE-SC0012088 and DE-SC0014416. We'd like to thank the Environmental Molecular Sciences Laboratory at Pacific Northwest National Laboratory (Richland, WA) for access to their 12T FTICRMS and for support to MM Tfaily. We thank the Abisko Scientific Research Station for sampling infrastructure and Kelsey Crossen for assistance with the microbial data from Sweden. SR Saleska and VI Rich received support through the Ecosystem Genomics Initiative, by the University of Arizona Technology and Research Initiative Fund, through the Water, Environmental and Energy Solutions Initiative. 
Hydrogenation in anaerobic environments as an electron sink

\section{References}

Bache, R., Pfennig, N., 1981. Selective isolation of Acetobacterium woodii on methoxylated aromatic acids and determination of growth yields. Archives of Microbiology 130, 255-261.

Barker, H.A., 1936. On the biochemistry of methane formation. Archives of Microbiology 7,404-419. doi,10.1007/BF00407413

Benner, R., MacCubbin, A.E., Hodson, R.W., 1984. Anaerobic biodegradation of the lignin and polysaccharide components of lignocellulose and synthetic lignin by sediment microflora. Applied and Environmental Microbiology 47(5), 998-1004

Blodau, C., Deppe M., 2012. Humic acid addition lowers methane release in peats of the Mer Bleue. Soil Biology and Biochemistry 52, 96-98.

Bridgham, S.D., H. Cadillo-Quiroz, J.K. Keller, Zhuang, Q., 2013. Methane emissions from wetlands, biogeochemical, microbial, and modeling perspectives from local to global scales. Global Change Biology 19, 1325-1346.

Burdige, D.J., 2006. Geochemistry of Marine Sediments, Princeton University Press, Princeton, NJ USA

Callaway, T.R., Martin, S.A., 1996. Effects of organic acid and monensin treatment on in vitro mixedd ruminal microorganism fermentation of cracked corn. Journal of Animal Science 74, 1982-1989.

Chanton, J. P., Fields, D., Hines, M.E., 2006. Controls on the hydrogen isotopic composition of biogenic methane from high-latitude terrestrial wetlands, Journal of Geophysysical Research 111, G04004, doi, 10.1029/2005JG000134.

Chanton, J.P., Glaser, P.H., Chasar, L.S., Burige, D.J., Hines, M.E., Siegel, D.I., Tremblay, L.B., Cooper, W.T., 2008. Radiocarbon evidence for the importance of surface vegetation on fermentation and methanogenesis on contrasting types of boreal peatlands. Global Biogeochemical Cycles 22, GB4022.

Chasar, L.S., Chanton, J.P., Glaser, P.H., Siegel, D.I., Rivers, J.S., 2000a. Radiocarbon and stable C isotopic evidence for transport and transformation of dissolved organic C. Dissolved inorganic C, and $\mathrm{CH} 4$ in a norther Minnesota peatland. Global Biogeochemical Cycles 14(4), 1095-1108

Chasar, L.S., Chanton, J.P., Glaser, P.H., Siegel, D.L., 2000b. Methane concentration and stable isotope distribution as evidence of rhizospheric processes, comparison of a fen and bog in the Glacial Lake Agassiz Peatland complex. Annals of Botany 86(3), 655-663.

Chesson, A., Stewart, C.S., Wallace, R.J., 1982. Influence of plant phenolic acids on growth and cellulytic activity of rumen bacteria. Applied and Environmental Microbiology 44(3), 597-603.

Clymo, R.S., 1987. The ecology of peatlands. Scientific Progress 71,593-614

Coates, J.D., Cole, K.A., Chakraborty, R., O'Connor, S.M., Achenbach, L.A., 2002. Diversity and ubiquity of bacteria capable of utilizing humic substances as electron donors for anaerobic respiration. Applied and Environmental Microbiology 68(5), 2445-2452.

Colberg, P.J., Young, L.Y., 1985. Anaerobic degradation of soluble fractions of [14C-lignin] lignocellulose. Applied and Environmental Microbiology 49(2), 345-349.

Conrad, R., Noll, M., Claus, P., Klose, M., Bastos, W.R., Enrich-Prast, A., 2011. Stable C isotope discrimination and microbiology of methane formation in tropical anoxic lake sediments. Biogeosciences 8,795-814.

Conrad, R., 1999. Contribution of hydrogen to methane production and control of hydrogen concentrations in methanogenic soils and sediments. Federation of European Microbiological Societies Microbiology Ecology 28, 193-202

Corbett, J.E., Tfaily, M.M., Burdige, D.J., Cooper, W.T., Glaser, P.H., Chanton, J.P., 2013. Partitioning pathways of $\mathrm{CO} 2$ production in peatlands with stable $\mathrm{C}$ isotopes. Biogeochemistry 114,327-340

Drake, H.L., M.A. Horn, Wust, P.K., 2009. Intermediary ecosystem metabolism as a main driver of methanogenesis in acidic wetland soil. Environmental Microbial Reports 1(5), 307-318

Duddleston, K.N., M.A. Kinney, R.P. Kiene, and M.E. Hines (2002) Anaerobic microbial biogeochemistry in a northern bog, acetate as a dominant metabolic end product. Global Biogeochemical Cycles 16(4), 111-119.

Frolking, S., Talbot, J., Jones, M.C., Treat, C.C., Kauffman, J.B., Tuittila, E.-S., Roulet, N., 2011. Peatlands in the Earth's 21st century climate system. Environmental Reviews 19, 371-396

Fuchs, G., Boll, M., Heider, J., 2011. Microbial degradation of aromatic compounds-from one strategy to four. Nature Reviews 9,803-817.

Greening, C., Boswas, A., Carere, C.R., Jackson, C.R., Taylor, M.C., Stott, M.B., Cook, G.M., Morales, S.E., 2015. Genomic and metagenomics surveys of hydrogenase distribution indicate $\mathrm{H} 2$ is a widely utilized energy source for microbial growth and survival. The International Society for Microbial Ecology Journal 1-17. 
Hydrogenation in anaerobic environments as an electron sink

Gupta, V., Smemo, K.A., Yavitt, J.B., Basiliko, N., 2012. Active methanotrophs in two contrasting North American peatland ecosystems revealed using DNA-SIP. Microbial Ecology 63, 438-445.

Hackett, W.F., Connors, W.J., Kirk, T.K., Zeikus, J.G., 1977. Microbial decomposition of synthetic 14C-labeled lignins in nature, lignin biodegradation in a variety of natural materials. Applied and Environmental Microbiology 33(1), 43-51.

Heitmann, T., Blodau, C., 2006. Oxidation and incorporation of hydrogen sulfide by dissolved organic matter. Chemical Geology 235, 12-20.

Heitmann, T., Goldhammer, T., Beer, J., Blodau, C., 2007. Electron transfer of dissolved organic matter and its potential significance for anaerobic respiration in a northern bog. Global Change Biology 13, 1771-1785.

Hines, M.E., Duddleston, K.N., Rooney-Varga, J.N., Fields, D., Chanton, J.P., 2008. Uncoupling of acetate degradation from methane formation in Alaskan wetlands, Connections to vegetation distribution. Global Biogeochemical Cycles 22,GB2017

Hodgkins, S.B., Tfaily, M.M., C.K. McCalley, T.A. Logan, P.M. Crill, S.R. Saleska, V.I. Rich, and J.P. Chanton (2014) Changes in peat chemistry associated with permafrost thaw increase greenhouse gas production. Proceedings of the National Academy of Sciences 111(16), 5819-5824

Hodgkins, S.B., Chanton, J.P., Langford, L.C., McCalley, C.K., Saleska, S.R., Rich, V.I., Crill, P.M., Cooper, W.T., 2015. Soil incubations reproduce field methane dynamics in a subarctic wetland. Biogeochemistry 126, 241-249

Hristov A.N., Oh, J., Firkins, J.L., Dijkstra, J., Kebreab, E., Waghorn, G., Makkar, H.P.S., Adesogan, A.T., Yang, W., Lee, C., Gerber, P.J., Henderson, B., Tricarico, J.M., 2013. Special topic - Mitigation of methane and nitrous oxide emissions from animal operations, I. A review of enteric methane mitigation options. Journal of Animal Science 91, 5045-5069.

Hsu, C.S., Qian, K., Chen, Y.C., 1992. An innovative approach to data analysis in hydroC characterization by online liquid chromatography spectrometry. Analytica Chimica Acta 264, 79-89.

Hughes, P.E., Tove, S.B., 1980. Identification of an endogenous electron-donor for biohydrogenation as alphatocopherolquinol. Journal of Biological Chemistry 255,4447-4452.

Imkamp, F., Muller, V., 2002. Chemiosmotic energy conservation with Na+ as the coupling ion during hydrogendependent Caffeate reduction by Acetobacterium woodii. Journal of Bacteriology 184(7), 1947-1951.

Jenkins, T.C., Wallace, R.J., Moate, P.J., Mosley, E.E., 2008. Board-invited review, Recent advances in biohydrogenation of unsaturated fatty acids within the rumen microbial ecosystem. Journal of Animal Science 86,397-412.

Kaiser, J.-P., Hanselmann, K.W., 1982. Fermentative metabolism of substituted monoaromatic compounds by a bacterial community from anaerobic sediments. Archives of Microbiology 133, 185-194.

Kappler, A., Benz, M., Schink, B., Brune, A., 2004. Electron shuttling via humic acids in microbial iron(III) reduction in a freshwater sediment. Federation of European Microbiological Societies Microbiology Ecology 47(1), 85-92

Kato, S., Chino, K., Kamimura, N., Masai, E., Yumoto, I., Kamagata, Y., 2015. Methanogenic degradation of ligninderived monoaromatic compounds by microbial enrichments from rice paddy field soil. Scientific Reports 5, 14295-14306

Keller, J.K., Bridgham, S.D., 2007. Pathways of anaerobic C cycling across an ombrotrophic-minerotrophic peatland gradient. Limnology and Oceanography 52(1), 96-107

Keller, J.K., Weisenhorn, P.B., Megonigal, J.P., 2009. Humic acids as electron acceptors in wetland decomposition. Soil Biology and Biochemistry 41(7), 1518-1522.

Keller, J.K., Takagi, K.K., 2013. Solid-phase organic matter reduction regulates anaerobic decomposition in bog soil. Ecosphere 4(5), 1-12.

Kemp, P., White, R.W., Lander, D.J., 1975. The hydrogenation of unsaturated fatty acids by five bacterial isolates from the sheep rumen, including a new species. Microbiology 90,100-114.

Kendrick, E., 1963. A mass scale based on $\mathrm{CH} 2=14.0000$ for high resolution mass spectrometry of organic compounds. Analytical Chemistry 35(13), 2146-2155

Kroger, A., Biel, S., Simon, J., Gross, R., Unden, G., Roy, C., Lancaster, D., 2002. Fumarate respiration of Wolinella succinogenes, enzymology, energetics and coupling mechanism. Biochimica et Biophysica Acta 1553, 23-38.

Krumholz, L.R., Bryant, M.P., 1985. Clostridium pfennigii sp. Nov. uses methoxyl groups of monobenzenoids and produces butyrate. International Journal of Systematic Bacteriology 35(4), 454-456.

Kujawinski, E.B., Behn, M.D., 2006. Automated analysis of electrospray ionization Fourier transform ion cyclotron resonance mass spectra of natural organic matter. Analytical Chemistry 78, 4363-4373. 
Hydrogenation in anaerobic environments as an electron sink

Lin, X., Tfaily, M.M., Steinweg, J.M., Chanton, P., Esson, K., Yang, Z.K., Chanton, J.P., Cooper, W.T., Schadt, C.W., Kostka, J.E., 2014a. Microbial community stratification linked to utilization of carbohydrates and phosphorous limitation in a boreal peatland at Marcell Experimental Forest, Minnesota, USA. Applied and Environmental Microbiology 80(1), 3518-3530.

Lin, X., Tfaily, M.M., Green, S.J., Steinweg, J.M., Chanton, P., Imvittaya, A., Chanton, J.P., Cooper, W.T., Schadt, C.W., Kostka, J.E., 2014b. Microbial metabolic potential for carbon ddegradation and nutritent (nitrogenaa nd phosphorous) acquisition in an ombrotrophic peatland. Applied and Environmental Microbiology 80(1), 3531-3540.

Lin,X., Handley, K.M., Gilbert, J.A., Kostka, J.E. 2015. Metabolic potential of fatty acid oxidation and anaerobic respiration by abundant members of Thaumarchaeota and Thermoplasmata in deep anoxic peat. The International Society for Microbial Ecology Journal 9, 2740-2744.

Lovley, D.R., Klugg, M.J., 1982. Intermediary metabolism of organic matter in the sediments of a eutrophic lake. Applied and Environmental Microbiology 43(3), 552-560

Lovley, D.R., Coates, J.D., Blunt-Harris, E.L., Phillips, E.J.P., Woodward, J.C., 1996. Humic Substances as electron acceptors for microbial respiration. Nature 382, 445-449.

McCalley et al., 2014. Methane dynamics regulated by microbial community response to permafrost thaw. Nature $514,23-40$

Mackie, R.I., Gilchrist, F.M.C., Heath, S., 1984. An in vivo study of ruminal micro-organisms influencing lactate turnover andd its contribution to volatile fatty acid production. Journal of Agricultural Science Cambriddge 103, 37-51.

McKain, N., Shingfield, K.J., Wallace, R.J., 2010. Metabolism of conjugated linoleic acids and 18, 1 fatty acids by ruminal bacteria, products and mechanisms. Microbiology 156,579-588.

Meckenstock, M., Mouttaki, H., 2011. Anaerobic degradation of non-substituted aromatic hydrocarbons. Current Opinions in Biotechnology 22(3), 406-414

Minor, E., Stephens, B., 2008. Dissolved organic matter characteristics within the Lake Superior watershed. Organic Geochemistry 39, 1489-1501.

Monav, R., Woodcroft, B.J., Kim, E.-H., McCalley, C.K., Hoddgkins, S.B., Crill, P.M., Chanton, J.P., Hurst, G.B., VerBerkmoes, N.C., Saleska, S.R., Hugenholtz, P., Rich, V.I., Tyson, G.W., 2014. Discovery of a novel methanogen prevalent in thawing permafrost. Nature Communications 5, 3212.

Nagaraja, T.G., Newbold, C.J., van Nevel, C.J., Demeyer, D.I., 1997. Manipulation of ruminal fermentation in P.N. Hobson (eds.) The Rumen Microbial Ecosystem, (pp. 523-632). Springer Netherlands

Neubauer, S.C., Megonigal, J.P., 2015. Moving beyond global warming potential to quantify the climatic role of ecosystems. Ecosystems 18, 1000-1013

Nilsson, M., Öquist, M., 2009. Partitioning litter mass loss into carbon dioxide and methane in peatland cosystems. In: Baird AJ, Belyea LR, Comas X et al (eds) Carbon cycling in northern peatlands. American Geophysical Union, Washington, DC, pp 131-144

Odier, E., Monties, B., 1983. Absence of microbial mineralization of lignin in anaerobic enrichment cultures. Applied and Environmental Microbiology 46(3), 661-665

Pervin, H.M., Dennis, P.G., Lim, H.J., Tyson, G.W., Batstone, D.J., Bond, P.L., 2013. Drivers of microbial community composition in mesophilic and thermophilic temperature-phased anaerobic digestion pretreatment reactors. Water Research 47, 7098-7108.

Porter, A.W., Young, L.Y., 2014. Benzoyl-CoA a universal biomarker for anaerobic degradation of aromatic compounds. Advanced Applied Microbiology 88, 167-203.

Roden, E.E., Kappler, A., Bauer, I., Jiang, J., Paul, A., Stoesser, R., Konishi, H., Xu, H., 2010. Extracellular electron transfer through microbial reduction of solid-phase humic substances. Nature Geoscience 3, 417-421.

Romanowicz, E.A., Siegel, D.I., Chanton, J.P., Glaser, P.H., 1995. Temporal variations in dissolved methane deep in the Lake Agassiz Peatlands, Minnesota. Global Biogeochemical Cycles 9(2), 197-212.

Rosenfeld, I.S., Tove, S.B., 1971. Biohydrogenation of unsaturated fatty acids. Journal of Biological Chemistry 246, 5025-5030.

Rudolph, H., Samland, J., 1985. Occurrence and metabolism of sphagnum acid in the cell walls of bryophytes. Phytochemistry 24(4), 745-749.

Schink, B., Stams, A.J.M., 2006. Syntrophism among prokaryotes. M. Dworkin, S. Falkow, E. Rosenberg, K.H. Schleifer, E. Stackebrandt (Eds.), The Prokaryotes, an evolving electronic resource for the microbiological community (edn 3rd), vol 2, Springer-Verlag (2006), pp. 309-335.

Schink, B., 1997. Energetics of syntrophic cooperation in methanogenic degradation. Microbiology and Molecular Biology Reviews 61(2), 262-280. 
Hydrogenation in anaerobic environments as an electron sink

Schmidt, O., Horn, M.A., Kolb, S., Drake, H.L., 2015. Temperature impacts differentially on the methanogenic food web of cellulose-supplemented peatland soil. Environmental Microbiology 17(3), 720-734.

Schmidt, O., Hink, L., Horn, M.A., Drake, H.L., 2016. Peat, home to novel syntrophic species that feed acetate- and hydrogen-scavenging methanogens. The International Society for Microbial Ecology Journal 10, 19541966.

Scott, D.T., McKnight, D.M., Blunt-Harris, E.L., Kolesar, S.E., Lovley, D.R., 1998. Quinone moieties act as electron acceptors in the reduction of humic substances by humics-reducing microorganisms. Environmental Science and Technology 32, 2984-2989.

Sieber, J.R., McInerney, M.J., Gunsalus, R.P., 2012. Genomic insights into syntrophy, the paradigm for anaerobic metabolic cooperation. Annual Reviews in Microbiology 66, 429-452.

Smemo, K.A., Yavitt, J.B., 2011. Anaerobic oxidation of methane, an underappreciated aspect of methane cycling in peatland ecosystems? Biogeosciences 8, 779-793.

Stenson, A.C., Marshall, A.G., Cooper, W.T., 2003. Exact masses and chemical formulas of individual Suwannee River fulvic acids from ultrahigh resolution electrospray ionization Fourier transform ion cyclotron resonance mass spectrometry. Analytical Chemistry 75, 1275-1284.

Tang, K., Page, J.S., and Smith, R.D., 2014. Charge competition and the linear dynamic range of detection in electrospray ioization mass spectrometry. Journal of the American Society of Mass Spectrometry 15, 1416-1423.

Tarvin, D., Buswell, A.M., 1934. The methane fermentation of organic acids and carbohydrates. Journal of the American Chemical Society 56(8), 1751-1755

Tchobanoglous, G., Kreith, F., 2002. Handbook of solid waste management. McGraw-Hill New York, NY USA.

Tfaily, M.M., Hamdan, R., Corbett, J.E., Chanton, J.P., Glaser, P.H., Cooper, W.T., 2013. Investigating dissolved organic matter decomposition in northern peatlands using complimentary analytical techniques. Geochimica et Cosmochimica Acta 112, 116-129.

Tfaily, M.M., Cooper, W.T., Kostka, J.E., Chanton, P.R., Schadt, C.W., Hanson, P. J., Iversen, C.M., Chanton, J.P., 2014. Organic matter transformation in the peat column at Marcell Experimental Forest, Humification and vertical stratification. Journal of Geosphysical Research: Biogeosciences 119(4), 661-675

Tfaily, M.M., Corbett, J.E., Wilson, R.M., Chanton, J. P., Glaser, P. H., Cawley, K. M., Jaffé, R., Cooper, W. T., 2015. Utilization of PARAFAC-Modeled Excitation-Emission Matrix 2 (EEM) Fluorescence Spectroscopy to Identify Biogeochemical Processing of Dissolved Organic Matter in a Northern Peatland. Photochemistry \& Photobiology 91, 684-695 doi10.1111/php.12448

Tschech, A., Pfennig, N., 1984. Growth yield increase linked to caffeate reduction in Acetobacterium woodii. Archives of Microbiology 137(2), 163-167.

Tveit, A.T., Urich, T., Frenzel, P., Svennig, M.M., 2015. Metabolic and trophic interactions modulate methane production by Arctic peat microbiota in response to warming. Proceedings of the National Academy of Sciences E2507-E2516

Ungerfeld, E.M., Kohn, R.A., 2006. The role of thermodynamics in the control of ruminal fermentation. Ruminant Physiology: Digestion, Metabolism and Impact of Nutrition on Gene Expression, Immunology and Stress, pp.55-85.

Updegraff, K., Pastor, J., Bridgham, S.D., Johnston, C.A., 1996. Environmental and substrate controls over C and nitrogen mineralization in northern wetlands. Ecological Applications 5(1), 151-163.

Valentine, D.W., Hollands, E. A., Schimel, D.S., 1994. Ecosystem and physiological controls over methane production in northern wetlands. Journal of Geophysical Research 99(D1), 1563-1571.

van Hulzen, J.B., Segers, R., van Bodegom, P.M., Leffelaar, P.A., 1999. Temperature effects on soil methane production, an explanation for observed variability. Soil Biology and Biochemistry 31, 1919-1929.

Vanwonterghem, I., Jensen, P.D., Rabaey, K., Tyson, G.W., 2015. Temperature and solid retention time control microbial population dynamics and volatile fatty acid production in replicated anaerobic digesters. Scientific Reports 5,8496-8504

Vogt, S., Lyon, E.J., Shima, S., Thauer, R.K., 2008. The exchange activities of [Fe] hydrogenase (iron-sulfurclusterfree hydrogenase) from ethanogenic archaea in comparison with the exchange activities of [FeFe] and [NiFe] hydrogenases. Journal of Biological Inorganic Chemistry 13,97-106 DOI 10.1007/s00775-007$0302-2$

Waldron, S., Lansdown, J.M., Scott, E. M., Fallick, A. E., Hall, A. J., 1999., The global influence of H isotopic composition of water on that of bacteriogenic methane from shallow freshwater environments. Geochimica et Cosmochimica Acta 63, 2237-2245. 
Hydrogenation in anaerobic environments as an electron sink

Wang, L.-Y., Nevin, K.P., Woodard, T.L., Mu, B.-Z., Lovley, D.R., 2016. Expanding the diet for DIET, electron donors supporting direct interspecies electron transfer (DIET) in defined co-cultures. Frontiers in Microbiology 7, 1-7.

Whiticar, M. J., 1999. C and hydrogen isotope systematics of bacterial formation and oxidation of methane. Chemical Geology 161, 291-314.

Whiticar, M. J., Faber, E., Schoell, M., 1986. Biogenic methane formation in marine and freshwater environments, $\mathrm{CO} 2$ reduction vs. acetate fermentation, Isotope evidence. Geochimica et Cosmochimica Acta 50, $693-$ 709.

Wilson, R.M., Hopple, A.M., Tfaily, M.M., S.D. Sebestyen, C.W. Schadt, L. Pfeifer-Meister, C. Medvedeff, K.J. McFarlane, J.E. Kostka, M. Kolton, R.K. Kolka, L.A. Kluber, J.K. Keller, T.P. Guilderson, N.A. Griffiths, J. P. Chanton, S.D. Bridgham, P.J. Hanson, P.J., 2016. Stability of peatland C to rising temperatures. Nature Communications 7, 13723.

Williams, C.J., Yavitt, J.B., Wieder, R.K., Cleavitt, N.L., 1998. Cupric oxide oxidation products of northern peat and peat-forming plants. Canadian Journal of Botany 76, 51-62.

Wright, E.L., Black, C.R., Cheesan, A.W., Drage, T., Large, D., Turner, B.L., Sjogersten, S., 2011. Contribution of subsurface peat to CO2 and CH4 fluxes in a neotropical peatland. Global Change Biology 17, 2867-2881.

Yavitt, J.B., Seidmann-Zager, M., 2006. Methanogenic conditions in northern peat soils. Geomicrobiology Journal 23,119-127.

Ye, R., Jin, Q., Bohannan, B., Keller, J.K., Bridgham, S.D., 2014. Homoacetogenesis, a potentially underappreciated C pathway in peatlands. Soil Biology and Biochemistry 68, 385-391.

Ye, R., Keller, J.K., Jin, Q., Bohannan, B.J.M., Bridgham, S.D., 2016. Peatland types influence the inhibitory effects of a humic substance analog on methane production. Geoderma 265,131-140.

Yu, Z.C., 2012. Northern peatland C stocks and dynamics, a review. Biogeosciences 9(10), p. 4071-4085.

Zeikus, J.G., Wellstein, A.L., Kirk, T.K., 1982. Molecular basis for the biodegradative recalcitrance of lignin in anaerobic environments. Federation of European Microbiological Societies Microbiology Letters 15(3), 193-197. 
Hydrogenation in anaerobic environments as an electron sink
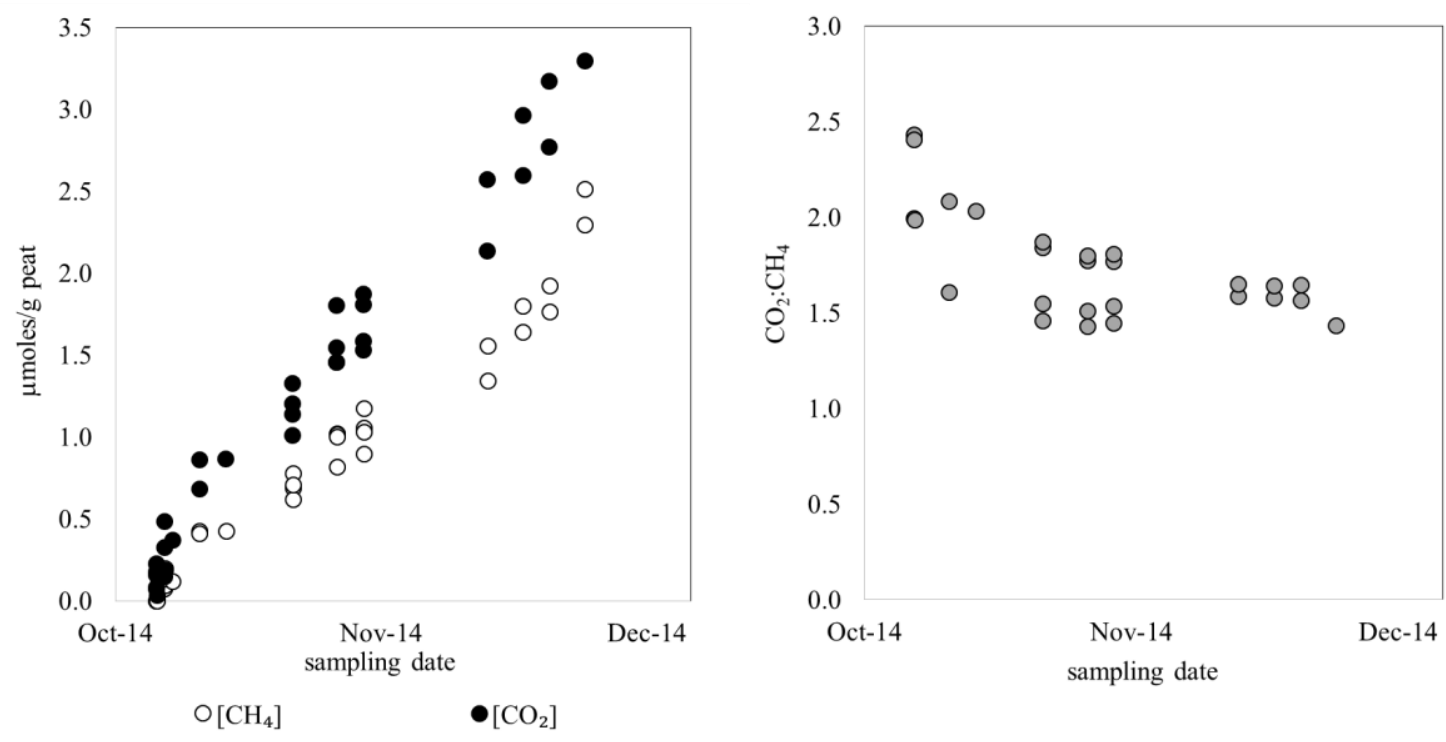

Fig. 1: $\mathrm{CO}_{2}$ and $\mathrm{CH}_{4}$ production (a) and $\mathrm{CO}_{2}: \mathrm{CH}_{4}$ production ratios (b) in the incubation experiment over time. Incubation days start counting following the pre-incubation period (day 0 ). Symbols indicate individual replicates measured over time. The number of replicates decreases over time as incubation vials were sacrificed for destructive sampling described in section 2. Materials and methods. 
Hydrogenation in anaerobic environments as an electron sink
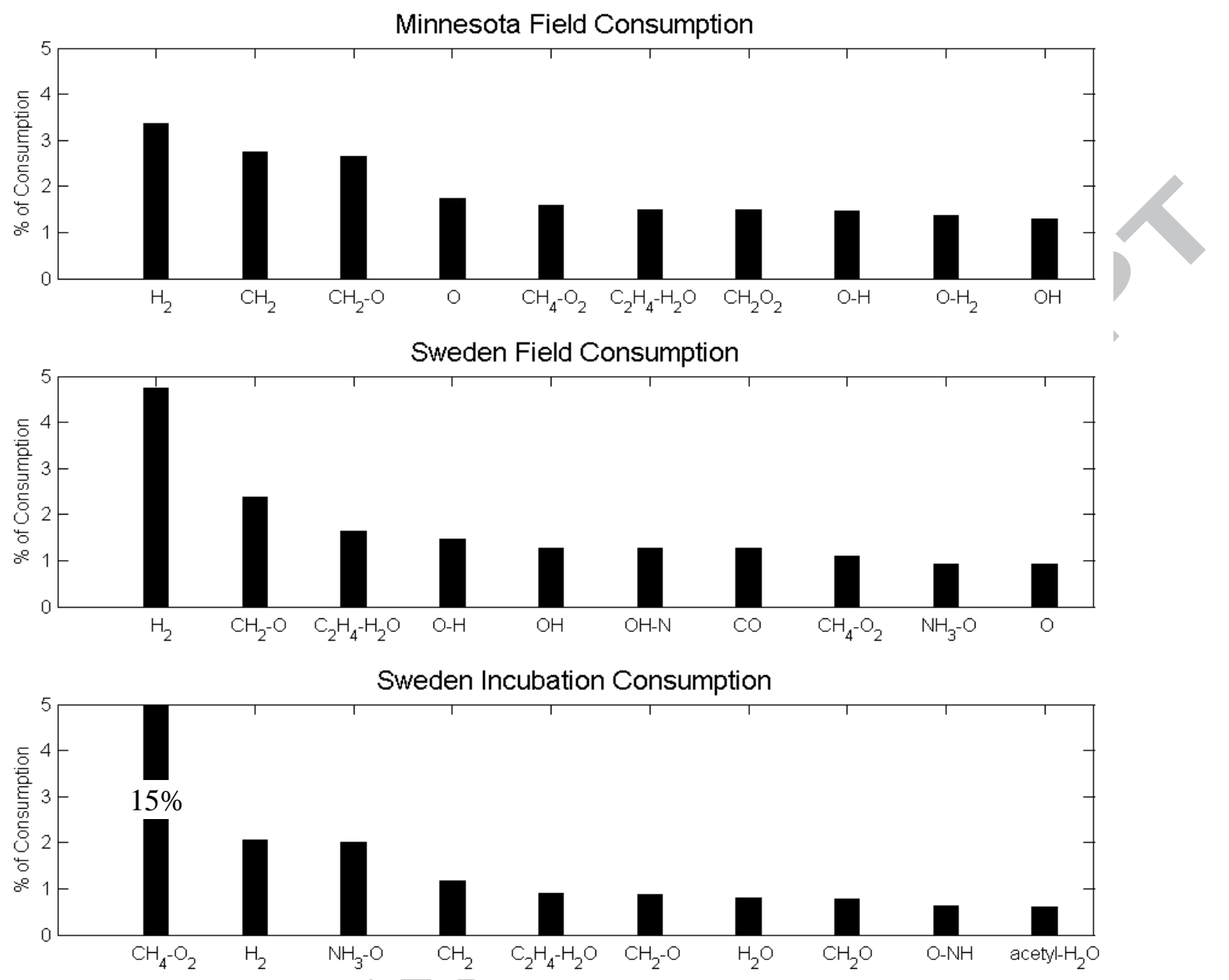

Fig. 2 Transform results in the field based on differences between shallow and deep samples for the Minnesota (a) and Sweden (b) peatlands. Panel (c) presents transform results for the incubations based on differences between day 0 and day 50 of the incubations. Transforms are ordered by frequency for each site. The dash (-) indicates exchange, for example $\mathrm{CH}_{2}-\mathrm{O}$ indicates a net exchange of $\mathrm{CH}_{2}$ for $\mathrm{O}$ in the molecule. Only the top ten most frequent transforms are shown. Note axes are truncated to $5 \%$ for comparison purposes, however, in the incubations graph $\mathrm{CH}_{4}-\mathrm{O}_{2}$ accounted for $15 \%$ (off scale) of total consumption. This transform is thought to represent the accumulation of $-2[\mathrm{H}],-\mathrm{CH}_{2}$, and $+\mathrm{O}_{2}$. 
Hydrogenation in anaerobic environments as an electron sink
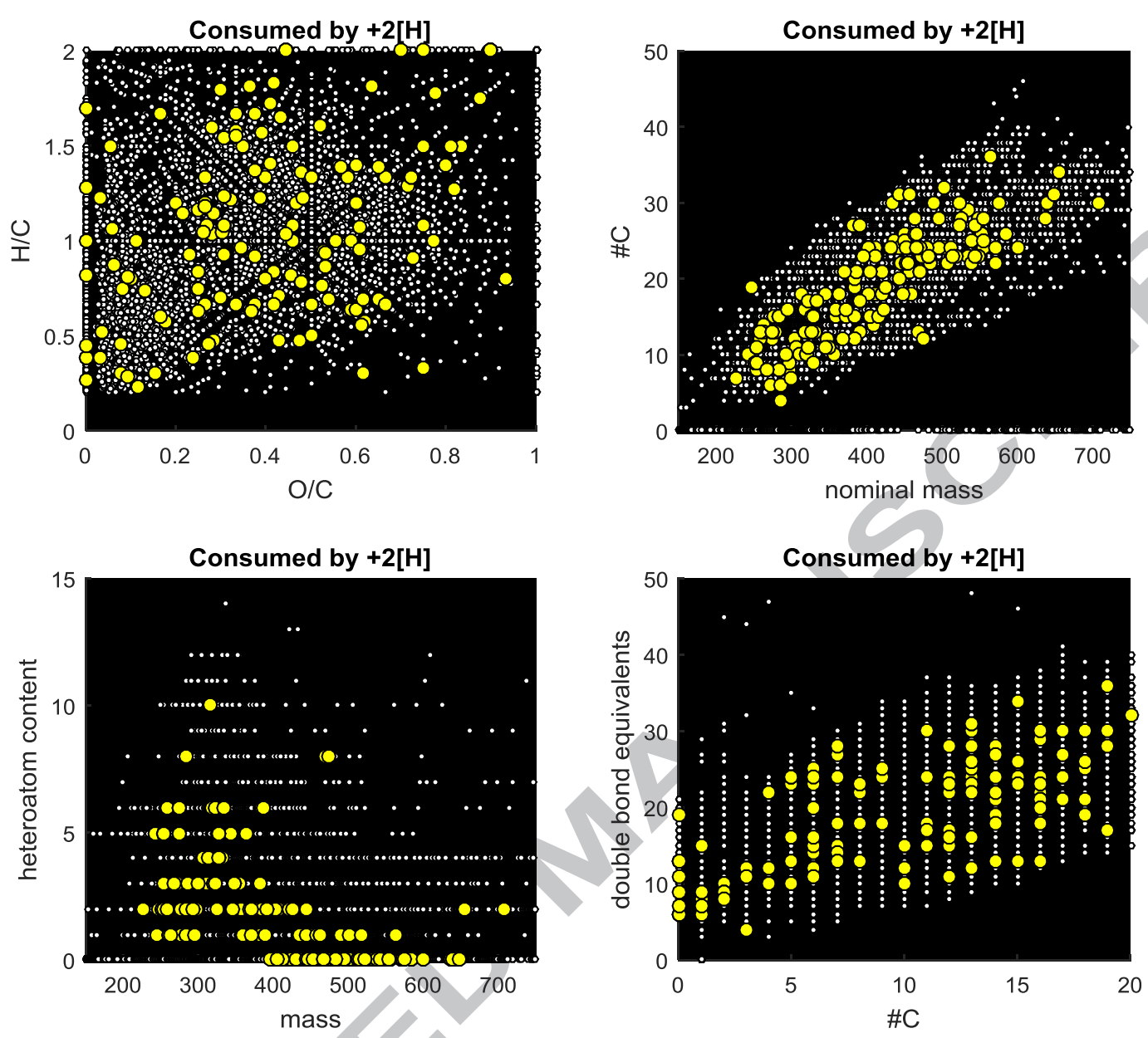

Fig. 3: Characteristics of all consumed compounds (incubations and both field sites combined) highlighting those compounds that are linked to $+2[\mathrm{H}]$ addition. In all panels, the yellow symbols indicate compounds that are consumed via addition of $+2[\mathrm{H}]$ and the grey symbols represent the molecular characteristics of all other compounds consumed by mechanisms other than $+2[\mathrm{H}]$. Panel (A) presents the van Krevelen diagram, Panel (B) presents the number of $\mathrm{C}$ atoms (\#C) vs. nominal mass, Panel (C) presents the total number of heteroatoms (N,S,P) vs. nominal mass, and Panel (D) presents the number of $\mathrm{C}$ atoms vs. double bond equivalents (DBE). No systematic differences between the chemical characteristics of $+2[\mathrm{H}]$ compounds (yellow) and those of compounds consumed by other mechanisms (grey) either in field sites or incubations was observed other than that there are fewer $+2[\mathrm{H}]$ additions at higher nominal mass and heteroatom content. 
Hydrogenation in anaerobic environments as an electron sink

Table 1: $\mathrm{CO}_{2}: \mathrm{CH}_{4}$ Ratios reported from field and incubation studies. Peat type are indicated by the abbreviations $\mathrm{CP}=$ collapsed palsa feature, $\mathrm{B}=$ Sphagnum-dominated bogs, and $\mathrm{F}=$ sedge-dominated Fen sites, the site investigated by Wright et al. (2011) was a Myrica-Cyrilla bog-plain, indicated with an asterisk (*).

\begin{tabular}{lllll} 
Reference & $\mathrm{CO}_{2}: \mathrm{CH}_{4}$ & Type of Study & Peat Type & Duration/depth \\
\hline Hodgkins et al. (2014) & 1.3 to 5 & Incubation & $\mathrm{CP}, \mathrm{B}, \mathrm{F}$ & 50 days \\
Hodgkins et al. (2015) & 5 to 10 & Field & CP, F, B & $0-22 \mathrm{~cm}$ \\
McCalley et al. (2014) & 1.2 to 5 & Field & $\mathrm{F}, \mathrm{B}$ & fluxes \\
Tfaily et al. (2014) & 2 to 100 & Incubation & B & 75 days \\
Corbett et al. (2012) & 6 to 15 & Incubation & F,B & $250-300$ days \\
Chasar et al. (2000a,b) & 4.6 to 12.8 & Field & F,B & $0-100 \mathrm{~cm}$ \\
Romanowicz et al. (1995) & 0.6 to 1.3 & Field & F,B & $0-250 \mathrm{~cm}$ \\
Valentine et al. (1994) & 10 to 20 & Incubations & F,B & $28-42$ days \\
Keller and Bridgham (2007) & 1.9 to 17 & Incubation & F,B & $3-4$ days \\
Wright et al. (2011) & 10 to $>20$ & Field & B* & $<200 \mathrm{~cm}$ \\
Updegraff et al. (1996) & 3.8 to 882.6 & Incubation & B & 560 days \\
van Hulzen, et al. (1999) & 1.7 to 10 & Incubation & F & 100 days \\
\hline
\end{tabular}


Hydrogenation in anaerobic environments as an electron sink

Figure Legends:

Fig. 1: $\mathrm{CO}_{2}$ and $\mathrm{CH}_{4}$ production (a) and $\mathrm{CO}_{2}: \mathrm{CH}_{4}$ production ratios (b) in the incubation experiment over time. Incubation days start counting following the pre-incubation period (day 0). Symbols indicate individual replicates measured over time. The number of replicates decreases over time as incubation vials were sacrificed for destructive sampling described in section 2. Materials and methods.

Fig. 2 Transform results in the field based on differences between shallow and deep samples for the Minnesota (a) and Sweden (b) peatlands. Panel (c) presents transform results for the incubations based on differences between day 0 and day 50 of the incubations. Transforms are ordered by frequency for each site. The dash (-) indicates exchange, for example $\mathrm{CH}_{2}-\mathrm{O}$ indicates a net exchange of $\mathrm{CH}_{2}$ for $\mathrm{O}$ in the molecule. Only the top ten most frequent transforms are shown. Note axes are truncated to 5\% for comparison purposes, however, in the incubations graph $\mathrm{CH}_{4}-\mathrm{O}_{2}$ accounted for $15 \%$ (off scale) of total consumption. This transform is thought to represent the accumulation of $-2[\mathrm{H}],-\mathrm{CH}_{2}$, and $+\mathrm{O}_{2}$.

Fig. 3: Characteristics of all consumed compounds (incubations and both field sites combined) highlighting those compounds that are linked to $+2[\mathrm{H}]$ addition. In all panels, the yellow symbols indicate compounds that are consumed via addition of $+2[\mathrm{H}]$ and the white symbols represent the molecular characteristics of all other compounds consumed by mechanisms other than $+2[\mathrm{H}]$. Panel (A) presents the van Krevelen diagram, Panel (B) presents the number of $\mathrm{C}$ atoms (\#C) vs. nominal mass, Panel (C) presents the total number of heteroatoms (N,S,P) vs. nominal mass, and Panel (D) presents the number of $\mathrm{C}$ atoms vs. double bond equivalents (DBE). No systematic differences between the chemical characteristics of $+2[\mathrm{H}]$ compounds (yellow) and those of compounds consumed by other mechanisms (white) either in field sites or incubations was observed other than that there are fewer $+2[\mathrm{H}]$ additions at higher nominal mass and heteroatom content. 
Hydrogenation in anaerobic environments as an electron sink

\section{Highlights}

- Organic matter hydrogenation provides an electron sink during anaerobic decomposition

- This mechanism sustains $\mathrm{CO}_{2}$ production and suppresses methanogenesis

- Thus this mechanism controls climate feedbacks by altering $\mathrm{CO}_{2}: \mathrm{CH}_{4}$ production ratios

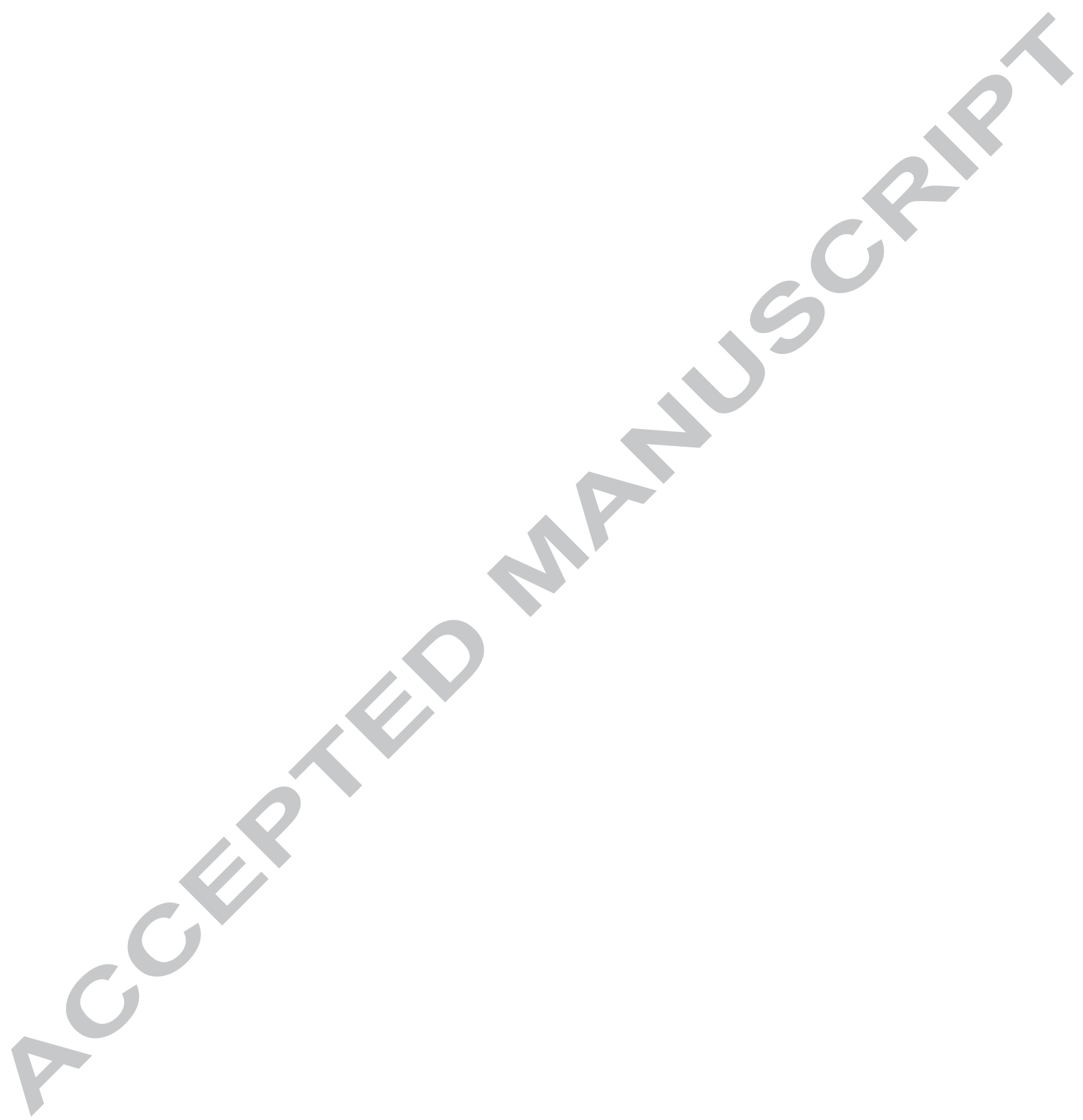

